\title{
The promoter of the Arabidopsis thaliana $B A N$ gene is active in proanthocyanidin-accumulating cells of the Brassica napus seed coat
}

\author{
Nathalie Nesi · Marie-Odile Lucas · Bathilde Auger · Cécile Baron · \\ Alain Lécureuil · Philippe Guerche · Jocelyne Kronenberger · \\ Loïc Lepiniec · Isabelle Debeaujon · Michel Renard
}

Received: 21 October 2008/Revised: 19 December 2008/Accepted: 30 December 2008/Published online: 20 January 2009

(C) The Author(s) 2009. This article is published with open access at Springerlink.com

\begin{abstract}
As part of an ongoing research program dedicated to the understanding of proanthocyanidin (PA) accumulation in Brassica napus seed coat, transgenic rapeseed plants carrying a $2.3-\mathrm{kb}$ fragment of the Arabidopsis thaliana BAN promoter (ProAtBAN) fused to the uidA reporter gene (GUS) were generated. Analysis of these plants revealed that ProAtBAN was activated in B. napus seed coat, following a spatio-temporal pattern that was very similar to the PA deposition profile in rapeseed and also to the one previously described in Arabidopsis. ProAtBAN activity occurred as soon as the early stages of embryogenesis and was restricted to the cells where PAs were shown to accumulate. Therefore, the Arabidopsis
\end{abstract}

N. Nesi and M.-O. Lucas contributed equally to this paper.

GenBank accession numbers for DNA sequences: EU192027 (BnTT8.1-mRNA), EU192028 (BnTT16.1-mRNA), EU192029 (BnTT16.2-mRNA), EU192030 (BnTTG1.1-CDS) and EU192031 (BnTTG1.2-CDS).

Communicated by L. Jouanin.

N. Nesi $(\square) \cdot$ M.-O. Lucas · B. Auger · C. Baron · M. Renard UMR118 INRA-Agrocampus Ouest-Université de Rennes1 Amélioration des Plantes et Biotechnologies Végétales, BP35327, 35653 Le Rheu Cedex, France

e-mail: nathalie.nesi@rennes.inra.fr

A. Lécureuil · P. Guerche

Institut Jean-Pierre Bourgin, UR254 INRA Station de Génétique et d'Amélioration des Plantes, INRA Centre de Versailles, 78026

Versailles Cedex, France

J. Kronenberger · L. Lepiniec · I. Debeaujon Institut Jean-Pierre Bourgin, UMR204 INRA-AgroParisTech Laboratoire de Biologie des Semences, INRA Centre de Versailles, 78026 Versailles Cedex, France
$B A N$ promoter can be used to trigger gene expression in $B$. napus seed coat for both genetic engineering and functional validation of candidate genes. In addition, these data strongly suggest that the transcriptional regulatory network of the BAN gene is conserved between Arabidopsis and rapeseed. This is consistent with the fact that similarity searches of the public rapeseed sequence databases allowed recovering the rapeseed homologs for several $B A N$ regulators, namely TT1, TT2, TT8, TT16 and TTG1, which have been previously described in Arabidopsis.

Keywords Brassica napus . Seed coat .

Proanthocyanidins $\cdot B A N$ promoter .

Regulation of flavonoid metabolism

\begin{tabular}{ll}
\multicolumn{2}{l}{ Abbreviations } \\
BAN & Banyuls \\
BuOH-HCl & Butanol-HCl \\
PAs & Proanthocyanidins \\
Dap & Day after pollination \\
DMACA & 4-Dimethylamino cinnamaldehyde \\
GUS & B-Glucuronidase \\
Hyg & Hygromycin B \\
TBO & Toluidine blue O \\
TT & Transparent Testa \\
$T T G$ & Transparent Testa Glabrous \\
$35 \mathrm{~S}$ & Cauliflower mosaic virus 35S
\end{tabular}

\section{Introduction}

Oilseed rape (Brassica napus L.) is an important oil crop that also provides a source of high quality proteins for animal feed. The molecular bases of seed development and 
maturation have been extensively covered in rapeseed, with a focus on the accumulation of seed storage compounds (reviewed in Hills 2004). On the contrary, data about the molecular and cellular events that underlie seed coat development are rather scarce although the testa significantly contributes to seed mass ( $\mathrm{Li}$ et al. 2006) and contains undesirable compounds that reduce the energy value of the oil-free seed cake (reviewed in Marles et al. 2003b). Indeed, the presence of oxidized dark pigments has anti-nutritive implications both in monogastric and ruminant livestock feeds (Martin-Tanguy et al. 1977; Kumar and Singh 1984). Since un-pigmented natural variants of $B$. napus have never been observed, yellow-seeded (YS) rapeseed lines with reduced pigment contents were developed through introgressions of the trait from related Brassica species for which YS genotypes naturally exist (B. rapa, B. juncea, B. carinata) (Rahman 2001). The resulting YS rapeseed genotypes display a reduction of their testa thickness that is correlated with higher contents in both oil and proteins, a lower content in fibres and therefore an improved meal nutritional value compared to their black-seeded counterparts (Simbaya et al. 1995; Slominski et al. 1999).
In Brassicaceae, the seed coat originates from the outer and the inner integuments of the ovule that subsequently go through different fates from fertilization onwards (reviewed by Haughn and Chaudhury 2005; Moïse et al. 2005). In B. napus seeds, the outer integument is composed of three parenchymatous cell layers surrounded by a one-layer epidermis (Wan et al. 2002). In very young seeds (around 6 days after pollination), the inner integument consists of a maximum of eight to ten cell layers that quickly undergo a reduction to one or two layers in the later developmental stages in association with programmed cell death (Wan et al. 2002). The innermost layer of the inner integument, known as the endothelium, accumulates phenolic compounds starting from the early stages of embryo development (Iwanowska et al. 1994). Seed pigments in mature dry seed of Brassica species are primarily oxidised proanthocyanidins (PAs; Fig. 1) (Durkee 1971) of the insoluble type (Naczk et al. 2000) constituted by cyanidin derivatives as basic units (Leung et al. 1979), very similar to those detected in seeds of the closely related model crucifer Arabidopsis thaliana (Devic et al. 1999; Routaboul et al. 2006). PAs originate from the flavonoid metabolic pathway

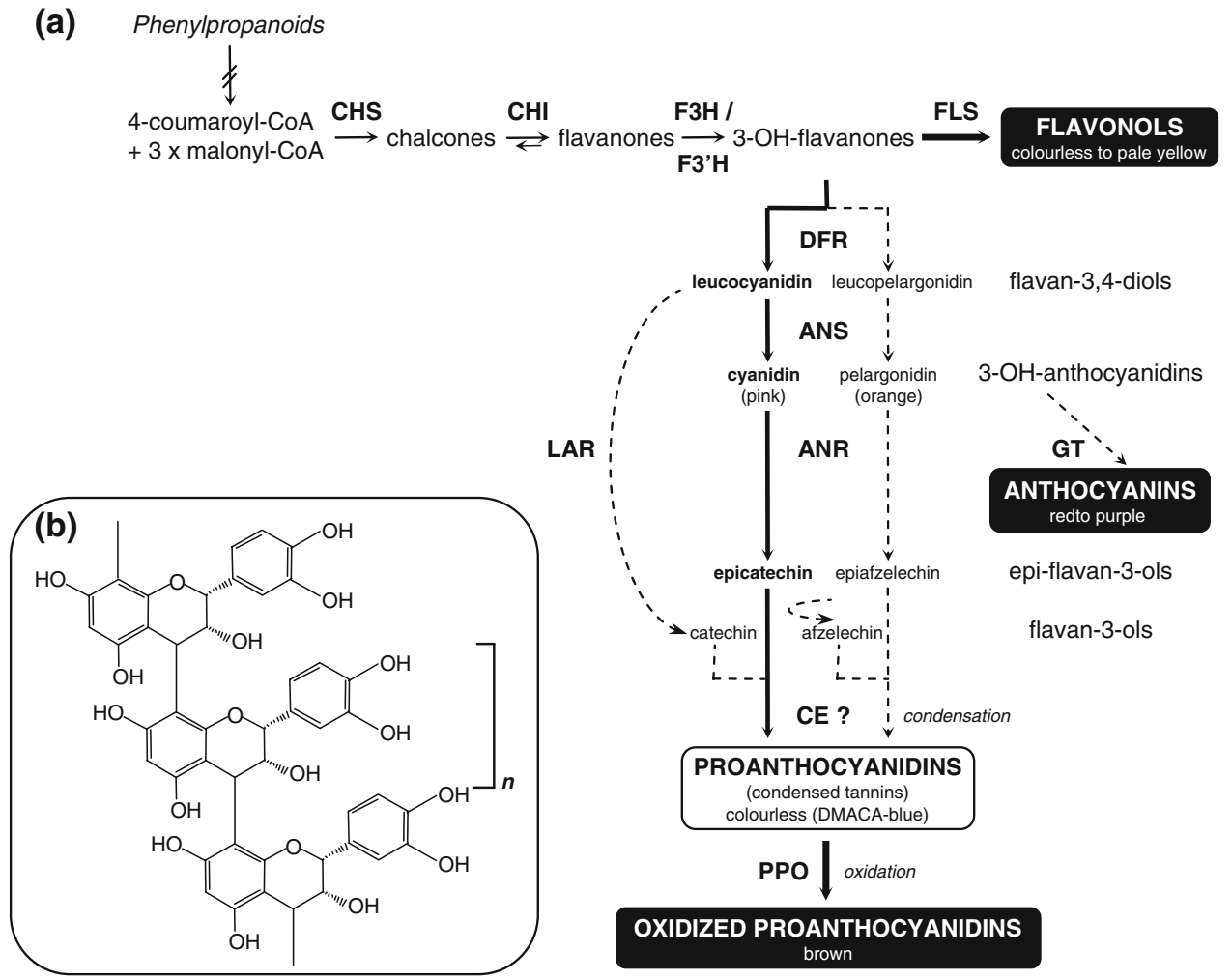

Fig. 1 Simplified overview of the flavonoid metabolic pathway with an emphasis on the proanthocyanidin (PA) biosynthetic branch. a PAs are derived from the flavonoid pathway. When applicable, the colours of the flavonoid compounds are indicated with or without chemical treatment. Dashed lines represent steps that were not detected in the testa of Brassicaceae seeds (Routaboul et al. 2006 and this study). ANR anthocyanidin reductase, ANS anthocyanidin synthase, $C E$ putative

condensing enzyme, $\mathrm{CHI}$ chalcone isomerase, $\mathrm{CHS}$ chalcone synthase, $D F R$ dihydroflavonol reductase, $F 3 H$ flavanone-3-hydroxylase, $F 3^{\prime} H$ flavonoid-3'-hydroxylase, $F L S$ flavonol synthase, $G T$ glucosyl transferase, $L A R$ leucoanthocyanidin reductase, $P P O$ polyphenol oxidase. $\mathbf{b}$ PAs encountered in the Brassica napus seed coat are $n$-polymers of epicatechin 
that also leads to the accumulation of pigments in vegetative parts (e.g., anthocyanins, flavonols) (Fig. 1a). During seed maturation, PAs form oxidized complexes with cell wall polysaccharides, other phenolics and/or proteins, thus imparting a dark colour to the seed tissues (reviewed in Moïse et al. 2005). A similar structure and development of the seed coat have been described for other Brassica species (Ren and Bewley 1998; Marles 2001; Zeng et al. 2004) and Arabidopsis thaliana (Devic et al. 1999; Beeckman et al. 2000; Debeaujon et al. 2003; Haughn and Chaudhury 2005), except that the number of cell layers per integument and the contribution of the seed coat to the total seed mass differ from one species to the other ( $\mathrm{Li}$ et al. 2006).

Unravelling the molecular basis of seed coat development in B. napus is of particular interest due to its economic importance for the final crop products. It requires genes with expression patterns exclusively restricted to the seed coat, and even ideally to a unique cell layer of the testa. For instance, deciphering and engineering PA metabolism will require endothelium-specific promoters that are active from the early stages of seed development onwards (Devic et al. 1999; Debeaujon et al. 2003). Although the use of Arabidopsis seed mutants has greatly improved our knowledge on testa development and biology (reviewed in Haughn and Chaudhury 2005), there are still only few reports about seed coat-specific genes in literature. To date, specific genes that have been identified in this field are the following ones: members of the barley germin gene family (Wu et al. 2000), subtilisin-like protease genes from soybean (SCS1; Batchelor et al. 2000) or rapeseed (Dong et al. 2004), a BURP-domain containing gene of soybean (SCB1; Batchelor et al. 2002), an aquaglyceroporin from pea (PSNIP-1; Schuurmans et al. 2003), several cystein endopeptidases associated with programmed cell death of either the outer integument in orchid (Nadeau et al. 1996) or the inner integument in rapeseed (BnCysPl; Wan et al. 2002) and in Arabidopsis ( $\delta V P E$; Nakaune et al. 2005), an epicatechin-specific glucosyltransferase in Medicago (UGT72L1; Pang et al. 2008), and some of the PA-related genes in Arabidopsis (TRANSPARENT TESTA [TT]-like genes; reviewed in Lepiniec et al. 2006). Among the 23 known TT-like loci, the BANYULS (BAN) gene is of particular interest. It encodes an anthocyanidin reductase (ANR) that constitutes the core enzyme of the PA biosynthetic pathway (Devic et al. 1999; Xie et al. 2003; Fig. 1a). In addition, activation of the $B A N$ promoter is restricted to PA-producing cells and is triggered by fertilization in the endothelium (Debeaujon et al. 2003). Therefore, the $B A N$ promoter is a powerful tool to investigate not only the regulation of PA-accumulating cell differentiation but also seed coat development in Arabidopsis. Since Arabidopsis thaliana is closely related to B. napus, one could assume that the basic genetic regulation that governs Arabidopsis seed coat development, and especially PA metabolism, will also apply to rapeseed. For instance, recent studies have shown that PA-related genes are highly conserved between Arabidopsis and rapeseed (Xu et al. 2006; Wei et al. 2007; Chai et al. 2008).

Taken together, these data prompted us to analyse the activity of the Arabidopsis thaliana BAN promoter in $B$. napus seeds. In the present study, seeds of $B$. napus transgenic plants carrying a $2.3-\mathrm{kb}$ fragment of the Arabidopsis BAN promoter fused to the uidA reporter gene (GUS) were analysed. The activation pattern of the Arabidopsis BAN promoter was consistent with the accumulation of PAs in B. napus and showed conservation between the two Brassicaceae. This demonstrated that the Arabidopsis BAN promoter could be used to trigger endothelium-restricted gene expression in rapeseed for genetic engineering as well as for functional genomics approaches. Finally, we present preliminary molecular data about the regulatory system that is likely to govern the activation of the Arabidopsis BAN promoter in rapeseed.

\section{Materials and methods}

\section{Plant material}

Brassica napus L. cv. Westar (spring genotype) was used for transformation assays in this study. Plants were grown in the greenhouse $\left(16 \mathrm{~h}\right.$ light at $22^{\circ} \mathrm{C} / 8 \mathrm{~h}$ dark at $18^{\circ} \mathrm{C}$; $200 \mu \mathrm{mol} \mathrm{m} \mathrm{m}^{-2} \mathrm{~s}^{-1}$ light intensity at the plant level), using a mixture of $20 \%$ black peat, $70 \%$ white peat and $10 \%$ perlit as substrate (Haasnoot Substraten, Zaltbommel, The Netherlands). Plants were vernalised for 4 weeks to ensure correct and homogenous flowering. Individual flowers on the primary raceme were manually pollinated and tagged on the day of pollination. Inflorescences were subsequently covered with a selfing bag to avoid cross pollination. Siliques were collected from individual plants at different stages of seed development from 5 to 35 days after pollination (dap). Seeds were carefully removed from siliques for histochemical and microscopic analyses.

Mature seeds were harvested at 50-60 dap (depending on the moisture level in the greenhouse), taking care to avoid precocious germination. For in vitro culture, seeds were surface-sterilised $20 \mathrm{~min}$ in $25 \%$ sodium hypochlorite plus $0.1 \%$ Tween- 20 added as a surfactant, and rinsed three times for $5 \mathrm{~min}$ in sterile deionised water. Sterile seeds were sown on full strength Murashige and Skoog (MS) medium ( $\mathrm{pH}=5.7$ ) with $30 \mathrm{~g} \mathrm{~L}^{-1}$ sucrose solidified with $2 \mathrm{~g} \mathrm{~L}^{-1}$ Gelrite (Duchefa Biochimie, Haarlem, The Netherlands), and placed into a growth room $\left(22 \pm 2^{\circ} \mathrm{C} ; 16\right.$ $\mathrm{h} / 8 \mathrm{~h}$ light/dark; $70 \mu \mathrm{mol} \mathrm{m}{ }^{-2} \mathrm{~s}^{-1}$ light intensity) to allow germination. 
Plasmids and Agrobacterium strains

Rapeseed explants were transformed with Agrobacterium tumefaciens C58C1Rif(pmp90) disarmed strain (Koncz et al. 1984) carrying the ProAtBAN: uidA/pBIB-Hyg binary vector or with Agrobacterium tumefaciens C58C1 pGV2260 bearing the Pro35S:uidA-intron/pBIN+binary vector (Vancanneyt et al. 1990) as a control. For ProAtBAN:uidA/ pBIB-Hyg, the T-DNA contains the hygromycin B phosphotransferase gene $(h p t)$ for in planta selection and a $2.3-\mathrm{kb}$ fragment of the Arabidopsis BAN promoter (hereafter named ProAtBAN) fused to the uidA gene that corresponded to the ProBAN1:uidA fusion described by Debeaujon et al. (2003). The bacterial strain was grown on LB supplemented with $50 \mathrm{mg} \mathrm{L}^{-1}$ rifampicin, $25 \mathrm{mg} \mathrm{L}^{-1}$ gentamycin and $50 \mathrm{mg} \mathrm{L}^{-1}$ kanamycin. For Pro35S:uidA-intron/pBIN+, the T-DNA contains the neomycin phosphotransferase II gene (nptII) for plant selection. The bacterial strain was grown on LB supplemented with $50 \mathrm{mg} \mathrm{L}^{-1}$ rifampicin, $50 \mathrm{mg} \mathrm{L}^{-1}$ carbenicillin and $50 \mathrm{mg} \mathrm{L}^{-1}$ kanamycin.

Agrobacterium-mediated rapeseed transformation and plant regeneration

Rapeseed genetic transformation was carried out according to Cardoza and Stewart (2003), using hypocotyls as explants. Hypocotyls were excised from 10-day-old seedlings grown in vitro, cut into $1-\mathrm{cm}$ pieces and preconditioned for $72 \mathrm{~h}$ on MS medium with $1 \mathrm{mg} \mathrm{L}^{-1} 2,4$ dichlorophenoxyacetic acid (2,4-D), $30 \mathrm{~g} \mathrm{~L}^{-1}$ sucrose and $2 \mathrm{~g} \mathrm{~L}^{-1}$ Gelrite. The pre-conditioned hypocotyl segments were dipped into an overnight suspension of Agrobacterium $\left(\mathrm{OD}_{600 \mathrm{~nm}}=0.8\right)$ that have been previously pelleted and re-suspended in liquid MS with $1 \mathrm{mg} \mathrm{L}^{-1} 2,4-\mathrm{D}$ and $30 \mathrm{~g} \mathrm{~L}^{-1}$ sucrose. The co-cultivation was conducted for 48 $\mathrm{h}$ on MS medium with $1 \mathrm{mg} \mathrm{L}^{-1}$ 2,4-D, $30 \mathrm{~g} \mathrm{~L}^{-1}$ sucrose and $2 \mathrm{~g} \mathrm{~L}^{-1}$ Gelrite. For selection of transformed cells, the explants were transferred for 2 weeks onto the co-cultivation medium supplemented with $400 \mathrm{mg} \mathrm{L}^{-1}$ timentin and $20 \mathrm{mg} \mathrm{L}^{-1}$ hygromycin (ProAtBAN:uidA/pBIB-Hyg) or $200 \mathrm{mg} \mathrm{L}^{-1}$ kanamycin (Pro35S:uidA-intron/pBIN+). To promote organogenesis, all explants were then transferred to the MS medium with $4 \mathrm{mg} \mathrm{L}^{-1}$ 6-benzylaminopurine (BAP), $2 \mathrm{mg} \mathrm{L}^{-1}$ zeatin, $5 \mathrm{mg} \mathrm{L}^{-1}$ silver nitrate, $30 \mathrm{~g} \mathrm{~L}^{-1}$ sucrose, $2 \mathrm{~g} \mathrm{~L}^{-1}$ Gelrite and antibiotics as mentioned previously. After a further 2 weeks, shoot development was induced by transferring the explants to MS medium with $3 \mathrm{mg} \mathrm{L}^{-1}$ BAP, $2 \mathrm{mg} \mathrm{L}^{-1}$ zeatin, $30 \mathrm{~g} \mathrm{~L}^{-1}$ sucrose, $2 \mathrm{~g} \mathrm{~L}^{-1}$ Gelrite and antibiotics. The developing shoots were transferred to MS medium with $0.05 \mathrm{mg} \mathrm{L}^{-1} \mathrm{BAP}$, $30 \mathrm{~g} \mathrm{~L}^{-1}$ sucrose, $2 \mathrm{~g} \mathrm{~L}^{-1}$ Gelrite and antibiotics, for shoot elongation promotion. The elongated shoots were excised from calli and transferred on rooting medium (half-strength MS salts, MS vitamins, $10 \mathrm{mg} \mathrm{L}^{-1}$ sucrose, $5 \mathrm{mg} \mathrm{L}^{-1}$ indole-3-butyric acid [IBA], $1 \mathrm{~g} \mathrm{~L}^{-1}$ Gelrite and $4.1 \mathrm{~g} \mathrm{~L}^{-1}$ plant agar, supplemented with $400 \mathrm{mg} \mathrm{L}^{-1}$ timentin and $20 \mathrm{mg} \mathrm{L}^{-1}$ hygromycin [ProAtBAN:uidA/ pBIB-Hyg] or $200 \mathrm{mg} \mathrm{L}^{-1}$ kanamycin [Pro35S:uidAintron/pBIN+]). Shoots were maintained on this medium until rooting. Finally, resistant rooted shoots were transferred to the greenhouse where they were maintained under propagator during the first 2 weeks to ensure correct acclimatization. All plant growth regulators and antibiotics were from Duchefa Biochimie.

\section{Molecular techniques}

Genomic DNA templates were prepared from resistant rooted plantlets grown in vitro by a simplified extraction protocol based on alkali treatment (Klimyuk et al. 1993) and adapted for rapeseed. Leaf pieces of $0.5 \mathrm{~cm}$ diameter were punched into an Eppendorf containing $200 \mu \mathrm{L} \mathrm{NaOH}$ $0.25 \mathrm{M}$ and quickly crushed before being boiled for $30 \mathrm{~s}$. The samples were incubated in $200 \mu \mathrm{L} \mathrm{HCl} 0.25 \mathrm{~N}$ and subsequently neutralised with $100 \mu \mathrm{L}$ of $0.5 \mathrm{M}$ Tris- $\mathrm{HCl}$ $\mathrm{pH} 8.0 ; 0.25 \%(\mathrm{v} / \mathrm{v})$ Triton X-100 before being boiled for a further $2 \mathrm{~min}$. Templates were then centrifuged and the supernatant was recovered and used for PCR analysis.

For gene expression analysis, tissue samples were ground in liquid nitrogen and total RNA was extracted with the SV Total RNA Isolation System (Promega, Madison, WI, USA) according to the instructions of the manufacturer. The extracts were treated with RNase-free DNase I (Promega) and eluted with $100 \mu \mathrm{L}$ of nuclease-free water. RNA integrity was checked onto a $1.5 \%(w / v)$ agarose electrophoresis gel and RNA concentration was measured with an Eppendorf BioPhometer. Absence of genomic DNA contamination was confirmed by PCR on $40 \mathrm{ng}$ of RNA using primers BnEF1-UP1 and BnEF1-RP1 (see below). For reverse transcription (RT)-PCR studies, $2.5 \mu \mathrm{g}$ of DNA-free RNA extract was converted into first-strand cDNA by using the SuperScriptII preamplification system for first-strand synthesis kit (Invitrogen, Glasgow, UK) and oligo(dT) $)_{12-18}$, following the manufacturer's recommendations. The cDNA samples were diluted tenfold and $1 \mu \mathrm{L}$ of dilution was tested by PCR with primers BnEF1-UP1 and BnEF1-RP1.

PCR reactions were conducted in a $20 \mu \mathrm{L}$ mixture containing 10-50 ng of DNA, $0.25 \mathrm{mM}$ of dNTPs (Promega), $0.5 \mu \mathrm{M}$ of each primers (Eurogentec, Angers, France) and $0.5 \mathrm{U}$ of Taq DNA polymerase (Promega) in the appropriate buffer $(1 \mathrm{X})$ supplemented with $2.5 \mathrm{mM}$ $\mathrm{MgCl}_{2}$. The amplification program was as following: 35 cycles of denaturation at $94^{\circ} \mathrm{C}$ for $30 \mathrm{~s}(3 \mathrm{~min}$ for the first cycle), annealing at $55-60^{\circ} \mathrm{C}$ for $30 \mathrm{~s}$, and elongation at $72^{\circ} \mathrm{C}$ for $1 \mathrm{~min} 30 \mathrm{~s}$ (10 min for the last cycle). 
Primers used in this study were as following : uidA-UP1 (5'-AATGGTGATTACCGACGAAAAC- $\left.3^{\prime}\right)$ and uidA-RP1 (5'-ATCAGCACGTTATCGAATCCTT- $\left.3^{\prime}\right)$ were designed from the E. coli UidA sequence and used to check for transgene insertion; T7 (5'-GTAATACGACTCACTA TAGGGC- $\left.3^{\prime}\right)$ and SP6 (5'-ATTTAGGTGACACTATAG AATA-3') were used to amplify the cDNA inserts from clones BN15023K07, BN20042P19 and BN25061A20; BnTTG1-ATG (5'-ATGGACAACTCAGCTCCGGACTC $\left.-3^{\prime}\right)$ and BnTTG1-Stop (5'-TCAAACTCTAAGGAGCTG CATTTTG- $3^{\prime}$ ) were used to amplify BnTTG1 coding sequences and to analyse the expression profile of BnTTG1; BnTT8-UP (5'-ATACTACAACGGCGCAATAAAG- $\left.{ }^{\prime}\right)$, BnTT8-RP (5'-GATGTGGAAACTGAATCTGAAAG-3'), BnTT16-ATG (5'-ATGGGAAGAGGGAAGATCGAAA T- $\left.3^{\prime}\right)$ and BnTT16-Stop (5'-TTAATCATTCTGGGCC GTTGGATC- $\left.3^{\prime}\right)$ were used to monitor the expression of BnTT8 and BnTT16 respectively; BnEF1-UP1 (5'-TCGA GACCACCAAGTACTACTGCAC-3') and BnEF1-RP1 (5'-GATCCTTGACAGCAACATTCTTAAC-3') were designed on the sequence of the BnEF1 EST (GenBank accession nb. CD827228), which encodes an ortholog from the Arabidopsis translation elongation factor EF-1 alpha chain (At5g60390) and were used as an internal control in gene expression analyses.

Colorimetric assays for qualitative detection of flavonoids in $B$. napus seeds

The DMACA histochemical assay (Li et al. 1996) is specific for detection of (epi)-flavan-3-ols and PA polymers. Immature seeds or deparaffined seed section were incubated in a freshly prepared solution of $0.3 \%(\mathrm{w} / \mathrm{v})$ DMACA (4dimethylamino cinnamaldehyde; ref. D-4506, SigmaAldrich Chemical) in a cold mixture of ethanol/12 N HCl $(1 / 1: \mathrm{v} / \mathrm{v})$ at room temperature for $1 \mathrm{~h}$. The samples were rinsed with $70 \%$ ethanol. A resulting blue coloration of the stained tissue is indicative of the presence of PAs. Observations and photographs were made under a low-power stereo microscope (SMZ-U, Nikon, Japan) equipped with a digital camera (Coolpix 950, Nikon, Japan).

For a rapid detection of both anthocyanins and PAs, a simplified butanol- $\mathrm{HCl}(\mathrm{BuOH}-\mathrm{HCl})$ protocol was adapted from Porter et al. (1986). Around 20 rapeseed integuments were crushed into an Eppendorf and flavonoids were extracted by $500 \mu \mathrm{L}$ of a mixture of methanol/acetone/ water/trifluoroacetic acid (40/32/28/0.05: v/v/v/v) during $15 \mathrm{~min}$ at RT. Three $\mathrm{mL}$ of $\mathrm{BuOH} / 12 \mathrm{~N} \mathrm{HCl}(95 / 5: \mathrm{v} / \mathrm{v})$ and $100 \mu \mathrm{L}$ of the ferric reagent $(2 \%$ ferric ammonium sulphate in $2 \mathrm{~N} \mathrm{HCl}$ ) were added to the samples that were subsequently boiled for $15 \mathrm{~min}$ and cooled on ice for a further $15 \mathrm{~min}$. A pink or orange coloration before boiling is consistent with the presence of cyanidin- or pelargonidin derivatives, respectively. A red to purple coloration after boiling indicates the presence of (epi)-catechin derived PAs (acid-hydrolysis cyanidin products).

\section{GUS assays}

GUS staining was performed according to Jefferson et al. (1987). Tissues were collected in $0.1 \mathrm{M}$ phosphate buffer $\mathrm{pH} 7.2$ (PB) and then prefixed by incubation in glacial $90 \%$ $(\mathrm{v} / \mathrm{v})$ aqueous acetone for $30 \mathrm{~min}$ at $4^{\circ} \mathrm{C}$. After three rinses in 0.1 M PB, samples were transferred into a fresh $\mathrm{PB}$ solution containing $2 \mathrm{mM} \mathrm{X}$-gluc (5-bromo-4-chloro-3indolyl- $\beta$-D-glucuronide; Duchefa Biochimie), $0.1 \%(\mathrm{v} / \mathrm{v})$ Triton X-100, $2.5 \mathrm{mM}$ each of potassium ferricyanide and potassium ferrocyanide, and $10 \mathrm{mM} \mathrm{Na}$-EDTA. Samples were vacuum infiltrated for $1 \mathrm{~h}$, incubated overnight at $37^{\circ} \mathrm{C}$ in the dark, and depleted of chlorophyll by incubation at room temperature in $70 \%$ ethanol. Stained samples were observed under a low-power stereo microscope.

\section{Microscopy}

Samples for resin embedding were directly fixed in $2 \%$ (v/v) glutaraldehyde and $1 \%(\mathrm{v} / \mathrm{v})$ paraformaldehyde in $0.1 \mathrm{M}$ PB under vacuum for $1 \mathrm{~h}$ and transferred to fresh fixative for $16 \mathrm{~h}$ at $4^{\circ} \mathrm{C}$. After fixation, the material was rinsed twice in $\mathrm{PB}$, dehydrated through a series of graded ethanol solutions (10, 30, 50, 70, 90, 100\%), and embedded in Technovit 7100 resin (Heraeus Kulzer Histo-Technik, Wehrheim, Germany) according to the manufacturer's instructions. The Technovit-embedded samples were sectioned to a thickness of $4 \mu \mathrm{m}$ using a rotary microtome (Jung RM 2055, Leica, Germany) equipped with metallic blades (Heraeus Kulzer). Sections were observed with a microscope (Axioskop2 Plus, Zeiss, Germany) under bright-field optics.

Selected sections were stained for $30 \mathrm{~s}$ in $0.5 \%(\mathrm{w} / \mathrm{v})$ toluidine blue $\mathrm{O}$ (TBO) in $0.1 \mathrm{M} \mathrm{PB}$, according to O'Brien et al. (1964), rinsed abundantly with water and observed under a microscope. The metachromatic stain TBO develops a blue-green colour in association with polyphenols (e.g., PAs, lignins) and stains the pectic substances in pink and the nucleic acids and proteins in purple.

Sequence analyses

Similarity searches of the databases were conducted according to Altschul et al. (1990) via the NCBI BLAST server (http://www.ncbi.nlm.nih.gov/blast/), where 458,264 B. napus expressed hits have been released (last update : 11 July 2008) and assembled through 26,733 clusters (Unigene Bna Build \#17). BLASTN option was used to recover rapeseed ESTs starting from Arabidopsis sequences. 
Similarity between probe and hit sequences was deemed significant if the BLASTN e-value was lower than $1 . e^{-68}$. Alignments were performed with the ClustalW algorithm and visualized with the BOXSHADE server (http://www. ch.embnet.org/software/BOX_form.html). The CAP3 DNA sequence assembly program (Huang and Madan 1999) available at http://pbil.univ-lyon1.fr/cap3.php was used to create EST contigs.

The cDNA clones BN15023K07, BN20042P19 and BN25061A20 were obtained from Genoplante rapeseed cDNA libraries BN15, BN20 and BN25 (Lib. IDs = Lib. 13977, 13978 and 13979, respectively) and used for sequencing with the following primers: $\mathrm{T} 7$ and BnTT16-UP5 (5'TCCGTCTGCGTCCATACCATGG-3') for BN15023K07 and BN20042P19; T7, BnTT8-UP2 (5'CAACGAACAAGGTCAAAGAGAGTG- $3^{\prime}$ ) and BnTT8UP3 (5'-GATGTTTTGTTAGAGATGAGATG- $\left.3^{\prime}\right)$ for BN25061A20. All DNA sequences were performed by Genome Express (Grenoble, France).

The GenBank accession numbers for the sequences mentioned in this study were as follows: M14641 (Escherichia coli UidA, $\beta$-glucuronidase); At1g61720 (Arabidopsis thaliana BAN, ANR); At1g34790 (Arabidopsis thaliana TT1, WIP-type Zn-Finger); At5g35550 (Arabidopsis thaliana TT2, AtMYB123); At4g09820 (Arabidopsis thaliana TT8, AtbHLH042); At5g23260 (Arabidopsis thaliana TT16/ABS, AtGL32); At5g24520 (Arabidopsis thaliana TTG1, WDrepeat protein); BN000703 (Medicago truncatula LAR); EU192027 (B. napus BnTT8.1-mRNA), EU192028 (B. napus BnTT16.1-mRNA), EU192029 (B. napus BnTT16.2-mRNA), EU192030 (B. napus BnTTG1.l-CDS) and EU192031 (B. napus BnTTG1.2-CDS).

\section{Results}

Nature, localization and time-course accumulation of pigments in developing B. napus seeds

Development of B. napus seed took around 45-50 days under our plant growth conditions, with the embryo reaching its final size between 20 and 25 days after pollination (dap; Fig. 2). Sequential embryo developmental stages can be characterized throughout seed development (Fig. 2, right column). At 5 dap, the embryo was at the globular stage (data not shown) and reached the heart to torpedo stage at 10-15 dap. A dramatic increase of embryo size between 15 and 18 dap led to the $\mathrm{U}$ shape stage (20 dap). At 25 dap, full size embryos were observed that was consistent with the end of sensu stricto embryogenesis. Maturation period included stick cotyledon embryo stage (30 dap). At 35 dap, embryos were fully mature. The first spots of brown pigmentation appeared on the seed body starting from 35 dap. At the basis of the seed close to the funiculus, a region appeared darker from early developmental stages onwards and corresponds to the micropylechalaza area (Fig. 2).

Differentiation of integuments occurred at the same time as embryo development. Seed sections stained with toluidine blue O (TBO) displayed the different cell layers of the seed integuments, namely the outer integument and the inner integument (Fig. 3a). The outer integument includes one epidermis (oi3), two-to-three parenchymatous cell layers (oi2) and one thick-walled palisade layer (oi1) (Fig. 3c). The outer integument persists as such until the appearance of the first pigmentation spots around 35 dap, when oi 2 begins to crush down (Fig. 3m). Mature outer integument primarily consists of oi3 stuck to oi1 (Fig. $3 \mathrm{~m}$ ). On the opposite, the inner integument is composed by five to seven parenchymatous cell layers (ii2; Fig. 3f) that rapidly crush down upon seed development (Fig. 3i, j), and by one cell layer called the endothelium (iil; Fig. 3f), which is the innermost cell layer of the inner integument. Mature inner integument consists of only iil (Fig. 3j-m). Variable numbers of parenchymatous cell layers in immature oi2 and ii2 depends (1) on the seed stage, since it is difficult to collect seeds exactly at the same stage and the number of cell layers rapidly decrease all along seed development especially for inner integument, and (2) on the location in the same seed (micropyle-chalaza pole versus seed body; Fig. 3a, b). Seed polyphenols accumulated within the endothelium as revealed by the blue-green colour observed from 15 dap (Fig. 3e, f) onwards (Fig. 3h-m) as well as within the chalaza region (Fig. 3b, d, e, g), referred to as the pigment strand according to Debeaujon et al. (2003). The accumulation of polyphenols in the pigment strand occurred earlier than in the endothelium cell layer, starting from 10 dap (Fig. 3b, d).

Developing seeds from B. napus were stained with DMACA reagent and the blue coloration obtained with this chemical was indicative of the presence of PAs (Fig. 4). These assays showed that PA deposition was restricted to the seed coat as the embryo remained unstained throughout seed development (Fig. 4e). In addition, when the seed was opened in two parts, the DMACA blue coloration seemed to be localised within the inner integument of the seed coat (Fig. 4d). Finally, although the seed body was uniformly stained with DMACA, the micropyle-chalaza region always appeared darker (shown by arrows in Fig. 4), even during the early stages of seed development when the embryo is at the globular to torpedo stage (10 dap; Fig. 4a). These findings were confirmed by staining a seed section with DMACA. A blue coloration appeared in the endothelium as well as within the pigment strand (Fig. 4f). During the time course 

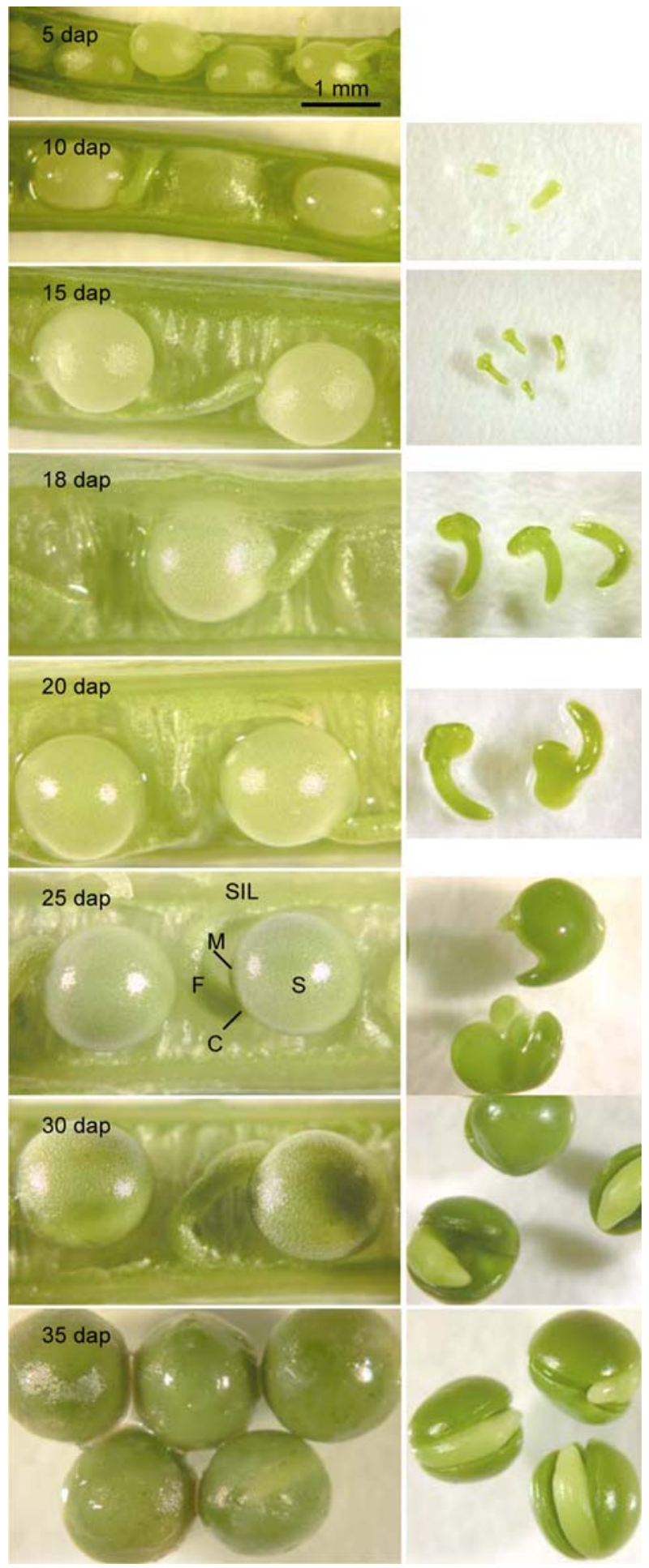

Fig. 2 Seed development in B. napus Westar cv. Whole seeds (left column) were regularly harvested from 5 to 35 days after pollination (dap). When possible, embryos (right column) were removed from seeds. Samples were observed under a low-power stereo microscope. Correspondence between embryo developmental stages and dap is as follows: 10 dap, late heart to torpedo; 15 dap, torpedo to late torpedo; 18 dap, U shape; 20 dap, late U; 25 dap, full size embryo; 30 dap, stick cotyledons; 35 dap, mature embryo. $C$ chalaza, $F$ funiculus, $M$ micropyle, $S$ whole seed, $S I L$ silique. Bar $1 \mathrm{~mm}$
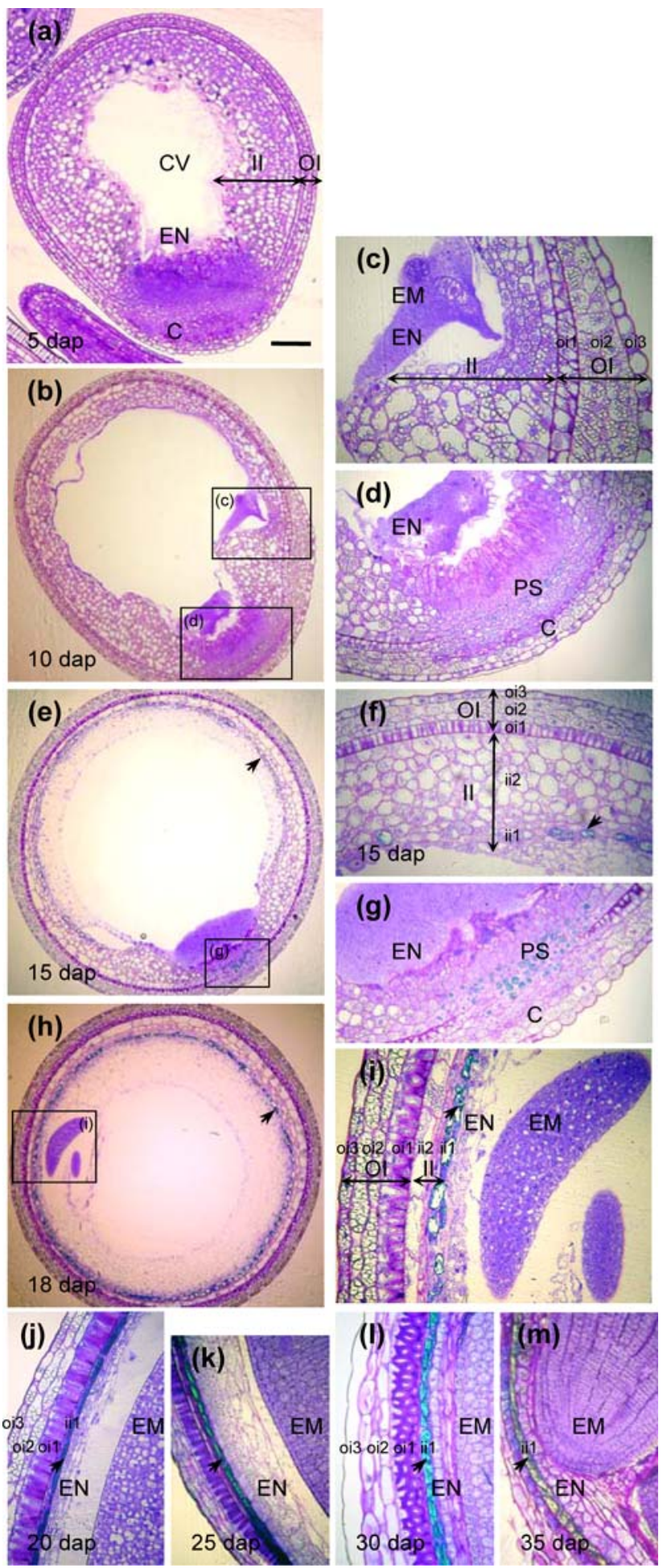

Fig. 3 Differentiation of integuments during seed development in B. napus. Sections $(4 \mu \mathrm{m})$ of developing seeds from Westar harvested from 5 to 35 dap were stained with toluidine blue $\mathrm{O}$ to localise the polyphenols. Samples were observed with a microscope under brightfield optics. Arrowheads indicate the pigmented cell layer of the inner integument (iil). $\mathbf{c}, \mathbf{d}, \mathbf{g}$ and $\mathbf{i}$ represent enlargements of $\mathbf{b}, \mathbf{e}$ and $\mathbf{h}$, respectively. $C$ chalaza, $C V$ central vacuole, $E M$ embryo, $E N$ endosperm, $I I$ inner integument, $O I$ outer integument, $P S$ pigment strand. Bar $125 \mu \mathrm{m}(\mathbf{a}) ; 250 \mu \mathrm{m}(\mathbf{b}) ; 400 \mu \mathrm{m}(\mathbf{e}, \mathbf{h})$ 

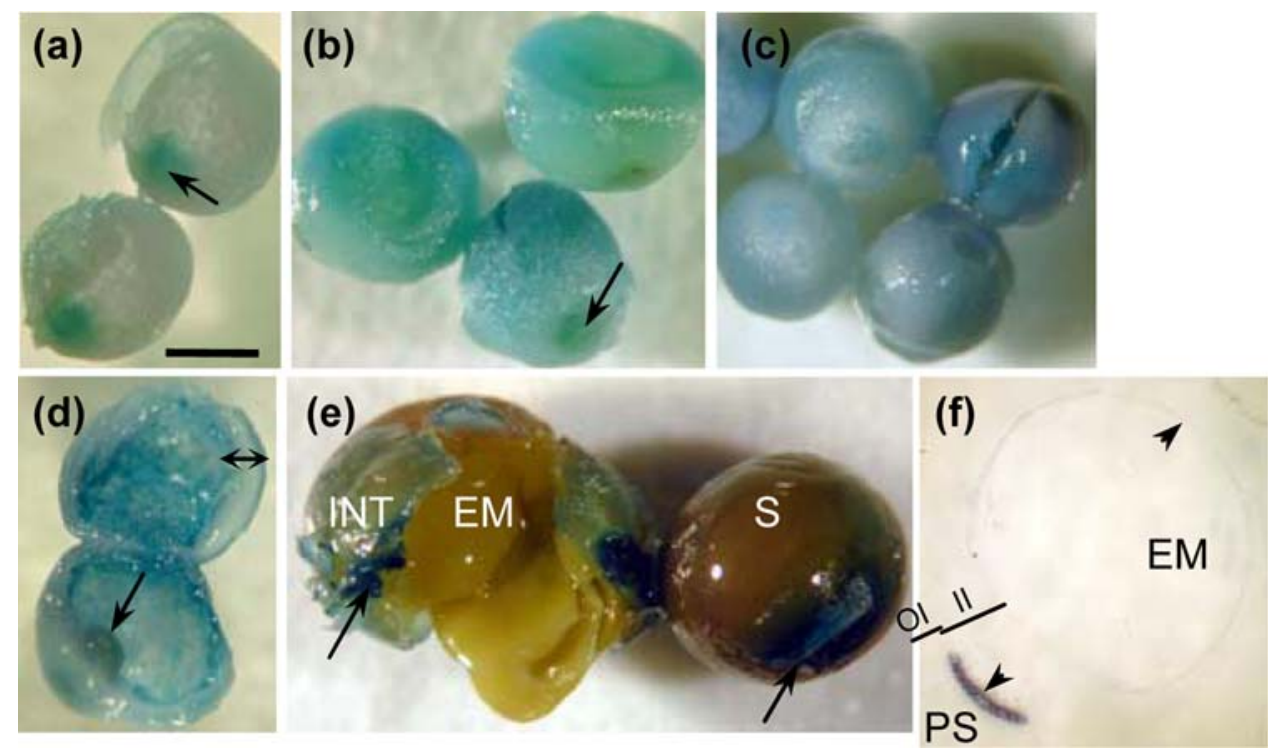

Fig. 4 Spatio-temporal pattern of proanthocyanidin deposition in B. napus immature seed. Proanthocyanidins were detected as blue coloration after staining with the DMACA reagent. Seeds were harvested at 10 dap (a), 18 dap (b, f), 20 dap (c, d) and 35 dap (e) and observed under a low-power stereo microscope after staining. Embryos were removed from the seed for samples collected at 20 dap (d) and 35 dap (e). Arrows point to the micropyle-chalaza region that always stained darker than the seed body. Double arrow in (d) shows the seed coat transversal section. Seed section in panel (f) $(10 \mu \mathrm{m})$ was deparaffined, stained with DMACA and observed under the low-power stereo microscope. Arrowheads in (f) indicate PA accumulation. EM embryo, II inner integument, INT integuments, $O I$ outer integument, $P S$ pigment strand, $S$ whole seed. Bar $0.4 \mathrm{~mm}(\mathbf{a})$; $0.6 \mathrm{~mm}(\mathbf{b}, \mathbf{d}, \mathbf{e}) ; 1 \mathrm{~mm}(\mathbf{c})$ of seed development, CT accumulation started from around 15-18 dap (Fig. 4b), which almost corresponded to mid-to-late embryogenesis under our plant growth conditions (refer to Fig. 2), and persisted during later stages of seed development (Fig. 4c-e).

A butanol- $\mathrm{HCl}(\mathrm{BuOH}-\mathrm{HCl})$ colorimetric assay was conducted on isolated seed coats to qualitatively evaluate the nature and amounts of PAs throughout seed development (Fig. 5). Samples turned to red-to-purple coloration after boiling (Fig. 5b), which indicated the presence of PAs derived from (epi)-catechin units. A very faint staining was observed starting from 15 dap, increased during mid-to-late embryogenesis (18-20 dap) and reached its maximum during seed maturation (25-45 dap). On the contrary, the $\mathrm{BuOH}-\mathrm{HCl}$ treated samples did not reveal any colour before boiling (Fig. 5a), suggesting that anthocyanins did not accumulate in B. napus seed coat.

To get further insights into the nature of PA units, we screened the B. napus genomic resources available through sequence databases using coding sequences from Arabidopsis BANYULS (BAN) and Medicago LAR genes, which encode ANR and leucoanthocyanidin reductase (LAR) respectively (Fig. 1a). Our preliminary results revealed the presence of at least four $B A N$ sequences in the rapeseed genome whereas no $L A R$ homolog was identified (data not shown).

Taken together these data showed that pigments found in B. napus seed coat were primarily PAs constituted by

\section{dap, days after pollination}

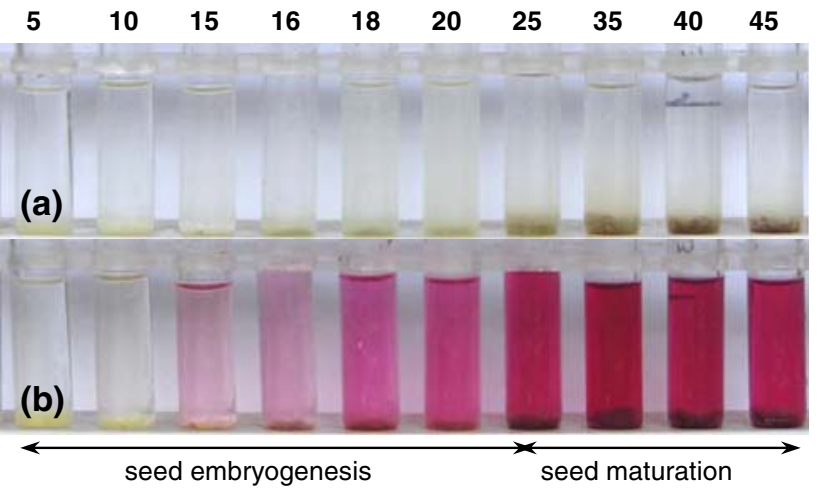

Fig. 5 Flavonoid detection in B. napus seed coat using $\mathrm{BuOH}-\mathrm{HCl}$ assays. Flavonoid extracts from $B$. napus integuments were submitted to a $\mathrm{BuOH}-\mathrm{HCl}$ colorimetric test to detect anthocyanins and proanthocyanidins. Observations were made before (a) and after (b) boiling the samples. The purple coloration after boiling indicates the presence of (epi)-catechin derived PAs

epicatechin units (Fig. 1b) whereas no anthocyanins were detected. In addition, PA deposition was restricted to the inner integument of the seed coat and to the micropylechalaza region. Finally, PA accumulation started from early embryogenesis (10 dap) in the micropyle-chalaza region and from mid-to-late embryogenesis (around 15-18 dap) in the seed body. It displayed a maximum level during seed maturation (25-35 dap). 
Activation pattern of Arabidopsis thaliana BAN promoter in B. napus seeds

Previous studies in Arabidopsis showed that ANR encoded by the $B A N$ gene played a central role in PA accumulation in seed (Devic et al. 1999; Debeaujon et al. 2003). In addition, the detailed analysis of the $B A N$ promoter using deletions revealed that its activation was restricted to PAproducing cells (Debeaujon et al. 2003). Taking advantages of this well-known system, we used a 2.3-kb fragment of the Arabidopsis BAN promoter fused to the reporter gene uidA (named ProAtBAN:uidA fusion, see "Materials and methods") to introduce into rapeseed. This promoter fragment involves the $5^{\prime}$-untranslated region of the $B A N$ gene.

For rapeseed transformation, we used the spring genotype Westar that displayed a high shoot regeneration potential $(80 \pm 2 \%$ explants giving a shoot) and a high susceptibility to Agrobacterium tumefaciens (45 $\pm 3 \%$ ) when compared to a large panel of rapeseed genotypes under our experimental conditions (M.-O. Lucas et al. unpub.). During the course of this study, a total of 400 explants were prepared for co-infection with Agrobacterium tumefaciens carrying the ProAtBAN:uidA/pBIB-Hyg binary vector. Thirteen hygromycin-resistant primary transformants (T1) were recovered of which eight set seeds in progeny. Transformation efficiency therefore reached $2 \%$ in this study. Presence of the transgene was double checked by PCR analysis using a piece of T1 plant leaf and by GUS staining of immature T2 seeds. In addition, T2 progeny from the eight transformants exhibited different segregation patterns on hygromycin selection medium (data not shown), indicating that they were produced as independent transformation events.

Six T1 plants were selected for a detailed analysis of ProAtBAN:uidA activation pattern in different organs and the GUS profiles were compared to those obtained with Pro35S:uidA-intron transgenic rapeseeds (Fig. 6 a-d). Our
Fig. 6 Activation pattern of ProAtBAN in B. napus transgenic plants. GUS staining of various organs from Westar plants transformed with either ProAtBAN:uidA/pBIB-Hyg (a left, b left, $\mathbf{c}, \mathbf{e}-\mathbf{j}$ ) or Pro35S: uidA-intron/pBIN+ (a right, b right, d). a 10-dayold seedlings; b open flowers; c, $\mathbf{d}$ young siliques (around 1-2 dap); $\mathbf{e}-\mathbf{j}$ immature seeds collected at 5 dap (e), 10 dap (f), 15 dap (g), 20 dap (h), and 25 dap $(\mathbf{i}, \mathbf{j})$. Seeds in $(\mathbf{h})$ and $(\mathbf{j})$ were opened to separate the integuments from each other and from the embryo. Double arrow in $\mathbf{h}$ shows the seed coat transversal section. Note that flowers (b) and seeds $(\mathbf{c}-\mathbf{j})$ originate from $\mathrm{T} 1$ plants while seedlings (a) were selected from the $\mathrm{T} 2$ generation after seed germinating using accurate selective agent. EM embryo, $F$ funiculus, $I I$ inner integument, $I N T$ integuments, $M$ micropyle, OI outer integument, SIL silique. Bars $1 \mathrm{~cm}$ in a; $0.5 \mathrm{~cm}$ in $\mathbf{b} ; 1 \mathrm{~mm}$ in $\mathbf{c}-\mathbf{g} ; 1.25 \mathrm{~mm}$ in $\mathbf{h}-\mathbf{j}$

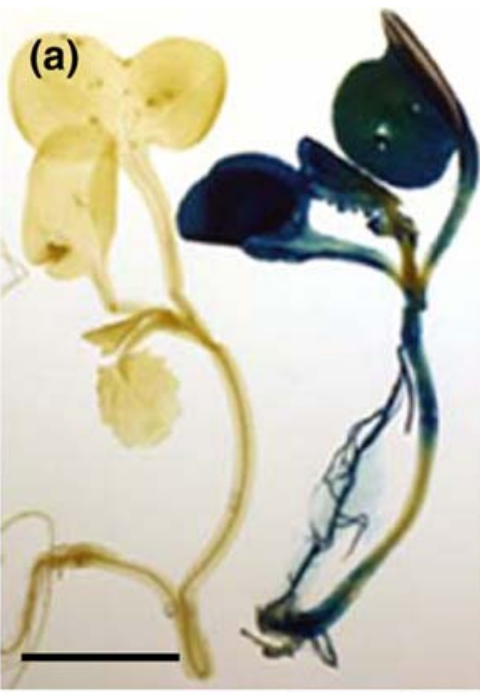

(b)
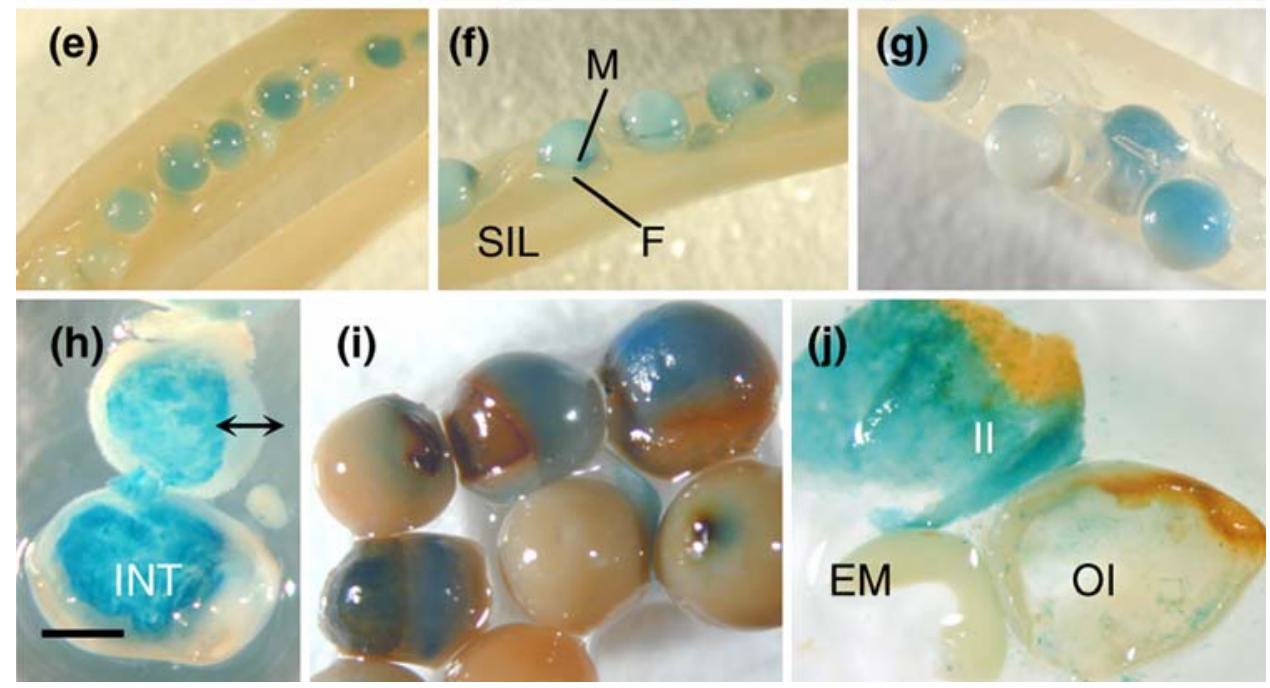
results demonstrated that GUS activity was undetectable in vegetative parts as well as in floral organs from ProAt$B A N$ :uidA plants (Fig. 6a, b) but was restricted to the seed (Fig. 6c). On the contrary, Pro35S:uidA-intron transgenic plants displayed GUS staining in whole seedlings, flowers and pod valves whereas the young seeds remained unstained except the funiculus (Fig. 6a, b, d).

Activation of ProAtBAN:uidA in B. napus seed was observed starting from very early developmental stages, as soon as 1-2 dap (Fig 6c), and persisted during the course of seed formation (Fig. 6e, f, g, i). At 25 dap, GUS staining appeared to be less homogenous from one seed to the other and even at the surface of a single seed (Fig. 6i), which could be explained by a reduced seed coat permeability towards chemicals.

Seeds at 20 and 25 dap were dissected to separate the integuments from the embryo. Samples showed that ProAtBAN:uidA expression was restricted to the seed coat as no staining was observed in the embryo (Fig. 6j). In addition, our results showed that all $\mathrm{T} 2$ seeds from ProAtBAN:uidA T1 plants were GUS positive within the silique (Fig. 6c-g), which was consistent with the fact that GUS expression was linked to the integuments. Finally, more precise observations suggested that GUS activity was specifically located within the inner integument (Fig. 6h, j), where PAs were shown to accumulate (Fig. 4f).
Fig. 7 Spatio-temporal pattern of ProAtBAN activity in

$B$. napus seeds. Sections $(4 \mu \mathrm{m})$ of developing seeds from

Westar plants transformed with ProAtBAN:uidA/pBIB-Hyg and stained for GUS activity were visualised with a microscope under bright-field optics. Seeds were harvested at 5 dap (a), 15 dap (b-d), and 25 dap (e, f). c, $\mathbf{d}$ and $\mathbf{f}$ represent enlargements of $\mathbf{b}$ and $\mathbf{e}$, respectively. The expression of ProAtBAN is restricted to the endothelium layer as shown by the arrowheads as well as to the chalaza region. For

abbreviations refer to Fig. 3 .

Bars $125 \mu \mathrm{m}$ in $\mathbf{a} ; 250 \mu \mathrm{m}$ in $\mathbf{b}$; $80 \mu \mathrm{m}$ in $\mathbf{e}$

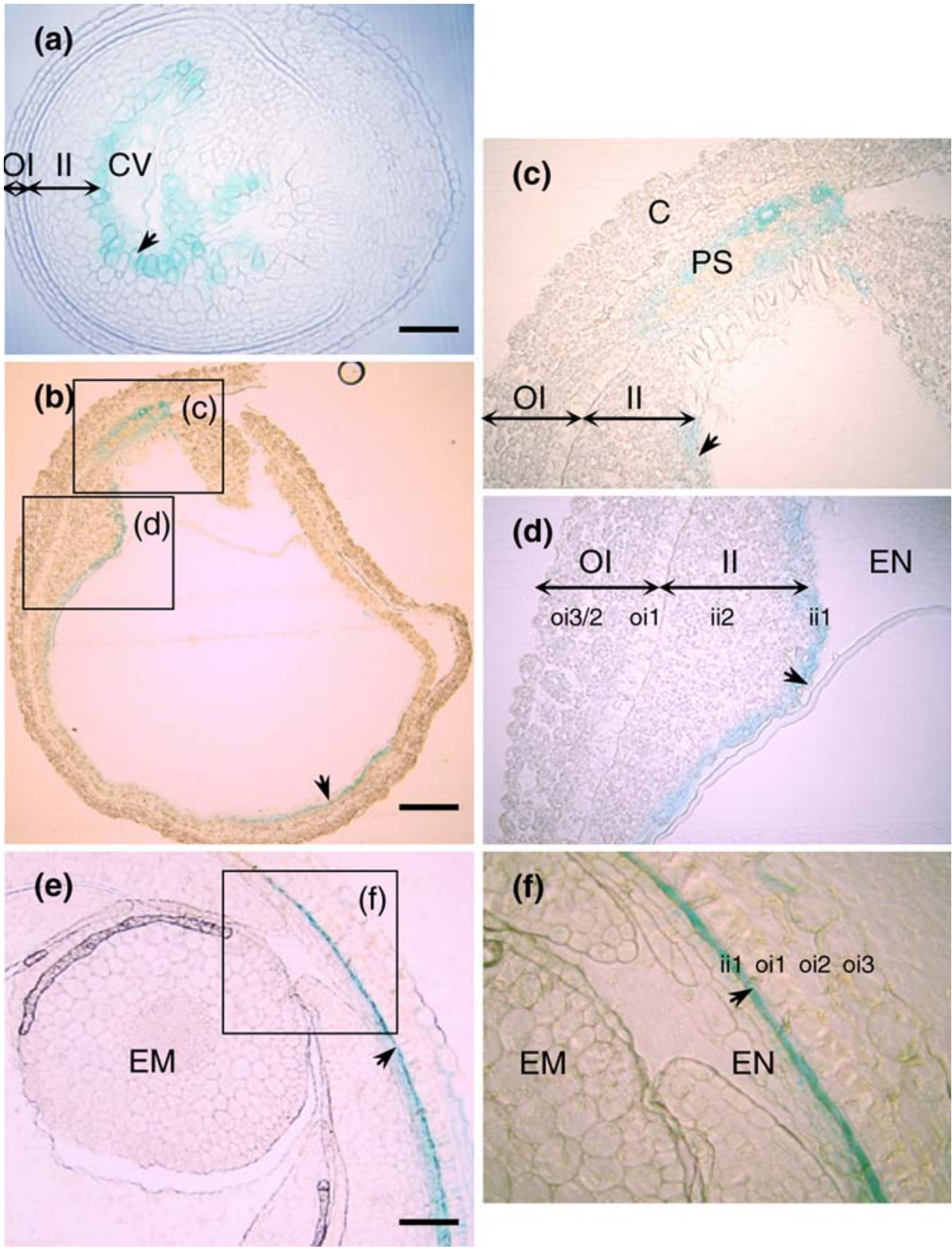


To monitor the tissue-specific location of ProAt$B A N$ :uidA activation pattern, GUS-expressing seeds taken at different developmental stages were resin-embedded and sections were produced for microscopic observations. GUS expression was localised in the innermost cell layer of the integuments (Fig. 7) as well as in several cell layers at the basis of the seed body (Fig. 7c). Comparison of GUS- and TBO-stained sections (Figs. 3 and 7, respectively) thereby demonstrated that GUS activity was restricted to the endothelium layer within the seed body and to the pigment strand within the chalaza area, where the PAs accumulated.

Altogether our results revealed that ProAtBAN was activated in $B$. napus seed in a fully consistent manner to the spatial PA accumulation pattern observed in this species. Indeed, ProAtBAN expression was restricted to PAaccumulating cells. Nevertheless, it is worthwhile to note that ProAtBAN expression occurred as soon as the globular embryo stage (around 5 dap; Fig. 7a) whereas PA accumulation began during mid-to-late embryogenesis (15-18 dap; Fig. 4).

Identification of rapeseed homologs for $B A N$ regulatory genes

In Arabidopsis, correct expression of $B A N$ requires at least five molecular components of which are the transcription factors TT1 (WIP-type Zn-Finger; Sagasser et al. 2002), TT2 (AtMYB123; Nesi et al. 2001), TT8 (AtbHLH042; Nesi et al. 2000) and TT16 (MADS AtAGL32; Nesi et al. 2002) as well as the regulatory factor TTG1 (WDR; Walker et al. 1999). Although ProAtBAN activation is altered in both $t t 1$ and $t t 16$ mutant seeds (Nesi et al. 2002; Debeaujon et al. 2003), the corresponding regulatory genes are likely to control cellular or tissue differentiation rather than PA metabolism directly (Nesi et al. 2002; Sagasser et al. 2002). On the contrary, Baudry et al. (2004)

Table 1 Identification of rapeseed homologs for three Arabidopsis PA regulatory genes

\begin{tabular}{|c|c|c|c|}
\hline $\begin{array}{l}\text { A. thaliana } \\
\text { gene }\end{array}$ & $\begin{array}{l}\text { B. napus EST cluster } \\
{\text { (Unigene acc. } \mathrm{nb} .)^{\mathrm{a}}}\end{array}$ & B. napus ESTs (GenBank acc. nb.) & $\begin{array}{l}\text { B. napus } \\
\text { transcripts }^{c}\end{array}$ \\
\hline TT8 & Bna.6320 [3; seed] & 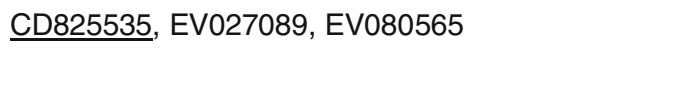 & $\begin{array}{l}\text { BnTT8.1-mRNA } \\
\text { (EU192027) }\end{array}$ \\
\hline \multirow[t]{3}{*}{ TT16 } & Bna.13305 [25; seed] & $\begin{array}{llll}\text { EE451062, } & E E 453231, & E E 453989, & E E 454628, \\
\text { EE455950, EE456757, EE458134, EE458355, } \\
\text { EE462069, EE462705, EE474660, EE476345, } \\
\text { EE478700, EE479023, EE564845, EE566135, } \\
\text { EV012102, EV021584, EV021863, EV022963, } \\
\text { EV025773, EV028865, EV035172, EV057167, } \\
\text { ES968264 }\end{array}$ & \multirow{3}{*}{$\begin{array}{l}\text { BnTT16.1-mRNA } \\
\text { (EU192028) } \\
\text { BnTT16.2-mRNA } \\
\text { (EU192029) }\end{array}$} \\
\hline & Bna.13731 [8; seed] & $\begin{array}{l}\text { EE455946, EE474346, EE474551, EE485285, } \\
\text { ES992355, EV023710, EV039605, EV070646 }\end{array}$ & \\
\hline & unclustered seq. [2; seed] & $\underline{\text { CD814606 }}, \quad \underline{\text { CD817735 }}$ & \\
\hline \multirow[t]{2}{*}{ TTG1 } & $\begin{array}{l}\text { Bna.15494 [11; seed, leaf, } \\
\text { microspore-derived } \\
\text { embryo] }\end{array}$ & $\begin{array}{l}\text { EE475976, EE541697, EE560829, ES268686, } \\
\text { ES921044, ES922727, EV047092, EV172875, } \\
\text { EV206821, EV207090, EV226364 }\end{array}$ & $\begin{array}{l}\text { BnTTG1.1-CDS } \\
(\text { EU192030) }\end{array}$ \\
\hline & & & $\begin{array}{l}\text { BnTTG1.2-CDS } \\
\text { (EU192031) }\end{array}$ \\
\hline
\end{tabular}

\footnotetext{
${ }^{a}$ Clusters are those defined through the Unigene Bna Build \#17 using 458,264 rapeseed ESTs. Number of ESTs per cluster is given into brackets as well as original tissues used to generate the corresponding cDNAs (written in italics)

${ }^{\mathrm{b}}$ ESTs that correspond to cDNA clones obtained from Genoplante and used for further sequencing are underlined. CD825535 correspond to cDNA clone BN25061A20; CD814606 to cDNA clone BN15023K07 and CD817735 to cDNA clone BN20042P19

${ }^{\mathrm{c}}$ Expressed sequences that were deposited into GenBank correspond to the longest sequences obtained during the course of this study. GenBank accession numbers are given into parentheses
} 
demonstrated that TT2, TT8, and TTG1 form a ternary complex that is likely to directly activate $B A N$ expression in planta and that TT2 and TT8 are able to bind to the BAN promoter when simultaneously expressed in yeast. These published data combined with the fact that ProAtBAN was active in $B$. napus seeds suggested that the regulatory network that controls $B A N$ expression is conserved between Arabidopsis and rapeseed. Recent studies demonstrated that three TT2 transcripts accumulated in B. napus seed (Wei et al. 2007). On the same line, several TTI transcripts were found in rapeseed (B. Weisshaar pers. comm.). In this study, we searched for additional rapeseed homologs of the $B A N$ regulatory genes by investigating public EST databases with Arabidopsis TT8, TT16 and TTG1 coding sequences as in silico probes.

For TT8, three rapeseed ESTs that belong to the same cluster (Bna.6320) were identified within the databases (Table 1). The B. napus BN25061A20 cDNA clone, which corresponded to EST CD825535, was obtained from a seed cDNA library produced by Genoplante (a major partnership French program in plant genomics). Sequencing of this cDNA clone (Jetneuf genotype) led to a 1,845-bp full length cDNA (BnTT8.1-mRNA), including a 40-bp polyA tail and a 1,566-bp coding sequence (data not shown). The translated BnTT8.1 sequence (521 residues) shared 78\% amino acid identity with AtTT8 (Fig. 8a). Residue conservation was observed all along the sequences and especially within the bHLH DNA-binding domains where identity between the two cruciferous sequences reached up to $88 \%$ (shown by the stars in Fig. 8 a).

For TT16, a total of 35 ESTs were recovered (Table 1) and two cDNA clones (BN15023K07 and BN20042P19) were obtained from Genoplante (Jetneuf genotype). Their sequencing allowed to identify full-length transcripts of 1,036 and 1,178-bp (BnTT16.1-mRNA and BnTT16.2mRNA respectively) including coding sequences of 720 and 726-bp (data not shown). The two proteins, named BnTT16.1 (240 residues) and BnTT16.2 (242 residues), shared $95.4 \%$ of residue identity among each other and 75 $78 \%$ of identity with AtTT16 (Fig. 8b). Both BnTT16 sequences displayed a typical 56-residue MADS box located at the N-terminus, followed by conserved I- (inter) and $\mathrm{K}$ - (keratin) domains. In addition, the C-terminal end contained a PI motif that was shown to be conserved among the MADS domain plant transcription factors from the B-sister monophyletic group (Becker et al. 2002; Nesi et al. 2002) (Fig. 8b).

For TTG1, one cluster including 11 ESTs was found in rapeseed (Table 1). Assembly of these sequences using CAP3 algorithm allowed defining a 1,357-bp contig including a 19-bp polyA tail (data not shown). Two primers were designed from the contig sequence (namely BnTTG1-ATG/BnTTG1-Stop) and used to amplify two
Fig. 8 Identification of rapeseed homologs for three Arabidopsis proteins involved in the regulation of PA biosynthesis. Alignments of the deduced amino acid sequences from Arabidopsis TT8 (a), TT16 (b) and TTG1 (c) with the corresponding rapeseed sequences retrieved after similarity searches of the public databases, sequencing of the complete cDNA clones and three-frame translation into protein sequences. Amino acids are numbered from the translation initiation codon onwards. Identical residues are highlighted in black and similar residues are shaded in grey. In a, the bHLH DNA-binding domains from both TT8 proteins are indicated by the stars above the sequences. In b, the MADS- (asterisks), I- (solidus), K- (reverse solidus), and PI- (cross symbol) domains are noted. The MADS domain corresponds to the DNA binding domain. In c, the two residues at the end of each WD repeat are boxed in red and the dashed line above the sequences indicates a proline-rich region of 26 residues. The accession numbers of the sequences used for the alignments are given in "Materials and methods"

coding sequences of 1,014 bp each (BnTTG1.1-CDS and BnTTG1.2-CDS) from a cDNA preparation of Jetneuf immature seeds. The deduced BnTTG1.1 and BnTTG1.2 amino acid sequences (337 residues) displayed more than 93\% identity with AtTTG1 (Fig. 8c). The four WD repeats found in AtTTG1 were retrieved in both B. napus homologs as well as a conserved proline-rich region of 26 residues (Fig. 8c).

These results demonstrated that homologs from Arabidopsis TT8, TT16 and TTG1 were present in the rapeseed genome and that the corresponding transcripts accumulated within B. napus seeds. In addition, rapeseed homologs displayed high sequence conservation with the corresponding Arabidopsis proteins.

Expression pattern of B. napus TT8, TT16 and TTG1 genes was monitored in different organs including roots, cotyledons, cauline leaves, floral buds and seeds from the Jetneuf genotype (Fig. 9). The present study was conducted with non-specific primers that allowed following the global expression level of $B$. napus orthologs for each one of the three target genes. Only BnTT16 transcripts were restricted to the seed, since BnTT8 and BnTTG1 genes were also expressed in plantlets (roots and/or cotyledons). In addition, a signal was observed in cauline leaves for BnTTG1. Our results also demonstrated that seed expression of the target genes was detected as early as 5 dap (even in floral buds for BnTT16 and BnTTG1) and was restricted to the integuments for BnTT8 and BnTT16 since no signal was observed in the embryo (Fig. 9).

\section{Discussion}

Proanthocyanidins accumulate in specific cells during B. napus seed development

Detection of flavonoids in B. napus seed coats was achieved by staining seeds collected at sequential developmental 
(a) TT8 alignment (bHLH-domain transcription factor)

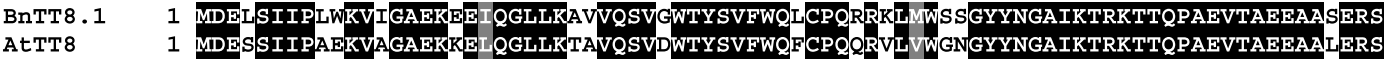

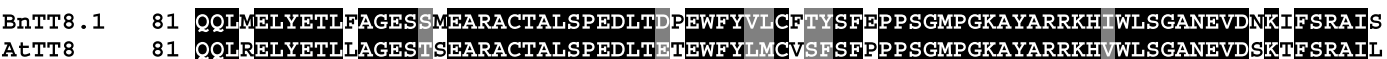

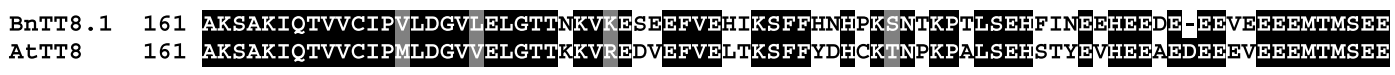
BnTT8.1 240 IRLGSPDDDVSNQNLLSDFHIEATNSLDTHMDMMNLMEEGGNYSQTVSTLLMSQPTSLLSDSVSTSSYVQSSFVSWRVE AtTT8 241 MRLGSPDD EDVSNQNLHSDLHIESTHLLDTHMDMMNLMEEGGNYSQTVHTLLMSHPTSLLSDSVSTSSYIQSSFATWRVE

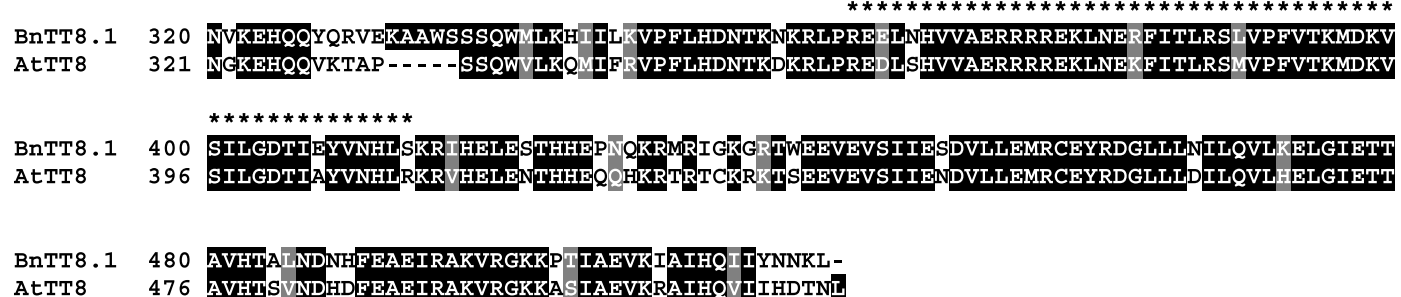

(b) TT16 alignment (MADS-domain transcription factor)
$\begin{array}{lll}\text { BnTT16.1 } & 1 \text { MGRGKIEIKRLENRTSRQVTFSKRRSGLIKKTHELSVLCDAHIGLIVFSATGKLTEYCSDPSKMPQLIERYLQTNGLRLP } \\ \text { BnTT16.2 } & 1 \text { MGRGKIEIKRIENRTSRQVTFSKRRSGLIKKTHELSVLCDAHIGLIVFSATGKLTEYCSDPSKMPQLIERYLQTNGLRLF }\end{array}$
$/ / / / / / / / / / / / / / / / /$

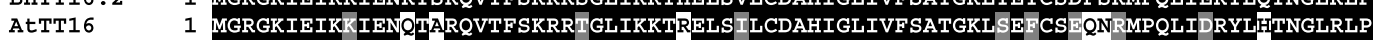

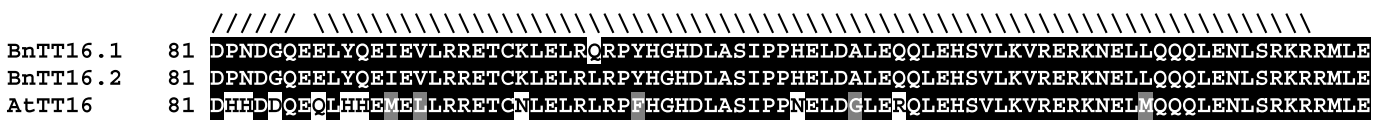
BnTT16.1 161 VDNSNMYRRLHEHGTAMEFQQAGIETKPGEYQQFLEQVQYYN- - - - EHQQQQQP - -PNSVLQLATLPSEIDPNYHLQLAQ BNTT16.2 161 DDNKNMYRWLHEHRTAMEFQQAGIETKPGEYQQFLEQVQYYN---- DHHQQQQQQPNSVLQLATLPSEIDPNYHLQLAQ $\begin{array}{lll}\text { AtTT16 } & 161 \text { EDNNNMYRWLHEHRAAMEFQQAGIDTKPGEYQQFTELLCYKPGEYQQFLEQQQQQPNSVLQLATLPSEIDPTYNLQLAQ }\end{array}$
BnTT16.1 $234 \stackrel{++++}{\text { PNLQNDN---- }}$
BnTT16.2 236 PNLQNDN-...
AtTT16 241 PNLQNDPTAQND

(MA* A -domain transcription factor)

(c) TTG1 alignment (WD-repeat protein)
BnTTG1.1 1 MDNSAPDSLPRSETAVTYDSPYPLYAMSFS- - -SSTHRIAVGSFLEDYNNRIDILSFDSDSMSLKPLPSLSFEHPYPPT BNTTG1.2 1 MDNSAPDSLPRSETAVTYDSPYPLYAMSFS - - - -SSTHRIAVGSFLEDYNNRIDILSFDSDSMSLKPLPSLSFEHPYPP AtTTG1 1 MDNSAPDSLSRSETAVTYDSPYPLYAMÄFSSLRSSSGHRIAVGSFLEDYNNRIDILSFDSDSMIVKPLPNLSFEHPYPPT




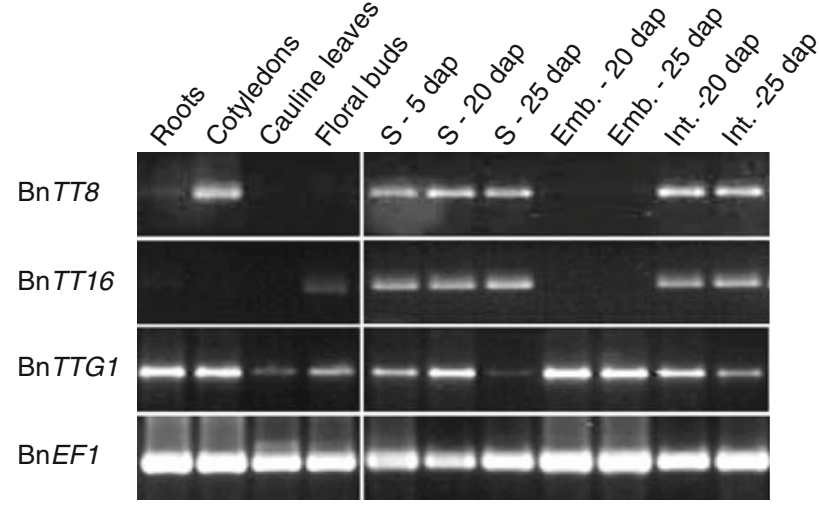

Fig. 9 Expression profiles of BnTT8, BnTT16 and BnTTG1 genes in $B$. napus. Transcript accumulation was monitored after 35 cycles of amplification using cDNA from roots, cotyledons from 10-day-old seedlings, cauline leaves, floral buds, whole seeds $(S)$ at 5, 20 and 25 dap, embryos (Emb.) at 20 and 25 dap, and integuments (Int.) from 20- and 25-dap seeds. Primers used in this study were designed to amplify the two BnTT16 or the two BnTTG1 coding sequences at the same time. PCR products were visualised after migration onto a $1.5 \%$ (w/v) agarose electrophoresis gel. The BnEF1 gene was used as an internal control to check for uniformity of cDNA loading

stages. Our results offered evidence that testa from B. napus developing seeds accumulated (epi)-catechin derived PAs, as demonstrated by the blue coloration with DMACA staining and the red-to-purple coloration of the $\mathrm{BuOH}-\mathrm{HCl}-$ treated flavonoid extracts. In addition, since no LAR was found in the rapeseed genome, one could hypothesize that epicatechin rather than catechin form PAs. On the contrary, no anthocyanins were detected. This corroborates previous data obtained with mature seeds of Brassica species (Leung et al. 1979; Naczk et al. 1994, 2000; Marles et al. 2003a; Marles and Gruber 2004). To date, seed coat flavonoids are still poorly characterized in rapeseed due to the difficulties of pigment extraction from the mature seed. Future prospects will therefore include the precise elucidation of the PA-basic unit, the determination of the mean degree of PA polymerization as well as the identification of flavonols using developing seeds instead of mature seeds as plant material.

PA accumulation was restricted to the seed coat, as previously shown for B. carinata (Marles et al. 2003a), and primarily to the innermost cell layer of the inner integument, called the endothelium layer (ii1), as revealed by DMACA-staining of seed sections. PAs also accumulate in the pigment strand cell layers within the chalaza region. PA-accumulating cells in Arabidopsis seed were also localized in the inner integument and the chalaza area (Debeaujon et al. 2003).

B. napus seed have two integuments, namely the outer integument (OI) and the inner integument (II), that differ in their structural organisation when compared with that of Arabidopsis thaliana seed integuments. The outer integument was delimited by one inside palisadic cell layer (oi1) and one outside epidermis (oi3), and also comprised twoto-three layers of parenchymatous cells (oi2), as described by Iwanowska et al. (1994). Cell walls from the palisade layer became very thick from 15-20 dap onwards. The inner integuments consisted of one endothelium (ii1) topped by numerous ( $>4$ ) parenchymatous cell layers (ii2) that underwent crushing during seed development. In the future, it will be useful to determine whether seed flavonoids in rapeseed accumulate in other cell layers than in the endothelium. Indeed, Pourcel et al. (2005) reported the presence of huge amounts of flavonols within the outer integument in Arabidopsis seed.

To our knowledge, less is known about the time-course of PA accumulation in rapeseed since most of the studies were conducted with mature seeds only (Naczk et al. 2000; Marles et al. 2003a; Marles and Gruber 2004). Here, we provided qualitative data about the PA accumulation pattern during seed development in B. napus. Accumulation of PAs and/or their precursors in the seed body began during mid-to-late embryogenesis (15-18 dap under our conditions) and subsequently underwent a dramatic increase as revealed by intense colorations observed with DMACA and $\mathrm{BuOH}-\mathrm{HCl}$ assays from 25 dap onwards. Pigmentation around the micropyle-chalaza region appeared to be under different genetic control than pigmentation within the seed body as it occurred earlier (as soon as 5 dap) and was darker. TBO- and DMACA-stainings of seed sections showed that polyphenolic compounds and more particularly PAs accumulated in several cell layers within the chalaza region. A very similar situation was reported for turnip rape and soybean seeds, in which one gene controlled pigment deposition in the hilum region specifically (Schwetka 1982; Todd and Vodkin 1993). In Arabidopsis, several of the $t t$ mutant seeds with pale brown to yellow seed bodies also exhibited a dark hilum (Debeaujon et al. 2001; 2003; Nesi et al. 2002), but regulators involved in pigment accumulation specifically in this area remain to be identified in the model plant. The occurrence of genetic controls specific to the development of the micropylehilum region may account for its critical roles, especially in being the seed-to-pod point of attachment and also in preventing early radicle protrusion.

Activity of the Arabidopsis thaliana BAN promoter in $B$. napus seeds reflects the PA accumulation pattern

Rapeseed transgenic plants carrying an Arabidopsis BAN promoter fragment fused to the uidA reporter gene displayed a GUS expression restricted to PA-accumulating cells, i.e. the endothelial cells as well as the micropylechalaza area. This activation pattern was fully consistent with the spatial deposition profile of PAs described here for B. napus seeds. This demonstrated that ProAtBAN could be 
used to trigger the expression of specific genes in B. napus PA-accumulating cells. Thereby, such a promoter will be very useful not only as a biotechnology tool but also to validate in planta the function of candidate genes. This will be very useful to improve our knowledge on seed coat development in B. napus, in particular on the formation of the pigmented cell layer. Indeed, very few seed-specific genes have been reported in literature, and especially less is known about genes that are specifically expressed in the testa.

Our results also showed that the ProAtBAN:uidA activation pattern was almost conserved between Arabidopsis and rapeseed, suggesting that functional homologs of ProAtBAN regulatory factors were present in rapeseed and were able to bind to and activate the Arabidopsis thaliana $B A N$ promoter. In addition, expression of ProAtBAN:uidA as soon as the onset of embryogenesis suggested that the complete PA regulatory mechanism was already present in early developmental stages (1-2 dap) of B. napus seed, even if PAs were shown to accumulate only from mid-tolate embryogenesis (15-18 dap). This delay may be due to post-transcriptional regulation events acting either at the level of mRNA (synthesis, stability,...) or at the level of protein (synthesis, activity,...).

The $B A N$ regulatory network is conserved between Arabidopsis thaliana and B. napus

To date, the development of genomic resources for Brassica species (e.g., ESTs, BAC libraries, B. oleracea and $B$. rapa genome sequencing programs) and the release of the produced data into the public databases offer the unique opportunity to quickly transfer the Arabidopsis knowledge to crops such as rapeseed. For instance, large sets of B. napus ESTs produced from numerous organs are now freely available. A total of 458,264 ESTs were released in the public databases and gathered into 26,733 clusters (Unigene Bna Build \#17 in July 2008), and can be used to initiate a candidate gene approach. During the progress of this work, BLASTN searches of the databases allowed to retrieve rapeseed ESTs starting with Arabidopsis TT8, TT16 and TTG1 coding sequences as in silico probes. EST alignments suggested that at least two rapeseed homeologous genes were found for TT8, TT16 and TTG1, that is consistent with the ploidy level of the B. napus genome. In addition, the opportunity to obtain rapeseed cDNA clones from Genoplante libraries for TT8 and TT16 hits allowed us to get the full-length corresponding expressed sequences that were more informative than the ESTs present in the databases. No rapeseed TTG1 cDNA clone was available from the Genoplante libraries, however contiguing the existing ESTs led to design accurate primers for amplification of the corresponding coding sequences. In the same time, other studies reported the molecular cloning of rapeseed $T T 1$ (B. Weisshaar pers. comm.) and TT2 (Wei et al. 2007), demonstrating that the five $B A N$ regulators described in Arabidopsis, namely TT1, TT2, TT8, TT16 and TTG1, were identified within the rapeseed genome.

Alignments of Arabidopsis and rapeseed amino acid sequences displayed high residue conservation rates, ranging from $71 \%$ for TT2 (Wei et al. 2007) to $93 \%$ for TTG1 (this study). In addition, the protein structures and putative functional domains (e.g., DNA binding domains) were highly similar between Arabidopsis and rapeseed sequences (Fig. 8 and Wei et al. 2007). However, it is worthwhile to note that the sequence conservation rates between the two plants were lower for the three transcription activation factors, TT2 (71\%), TT8 (79\%) and TT16 (75-78\%), than for the regulatory factor TTG1 (93\%). This could be due to the fact that TTG1 has a pleiotropic role, controlling not only the flavonoid biosynthetic pathway but also the development of trichomes and root hairs as well as the accumulation of seed mucilage (Koornneef 1981; Walker et al. 1999). We can therefore hypothesize that selective pressure during plant evolution was higher upon the TTG1 sequence compared to the three other proteins.

Although the selected sequences from Arabidopsis and rapeseed displayed high conservation rates at the structural level, the question remains to be addressed whether the B. napus hits represent functional orthologs of Arabidopsis proteins. At least two lines of evidence argued in favour of functional orthologs between the two Brassicaceae. First, the results presented in the current study demonstrated that ProAtBAN was activated in B. napus seed in a similar way than this described in Arabidopsis. Therefore, this suggested that rapeseed proteins were able to correctly bind to and activate the Arabidopsis BAN promoter sequence. Second, in an ongoing study, we showed that at least BnTT2, BnTT16 and BnTTGl were able to restore the wild-type phenotype when introduced into the corresponding Arabidopsis null mutants under the control of either a constitutive or a specific promoter (Auger et al. in prep.). This definitively proved that the identified BnTT proteins are functional orthologs from their Arabidopsis counterparts.

Finally, analysis of expression profiles for BnTT8, BnTT16 and BnTTG1 in B. napus revealed that BnTT8 and BnTTG1 transcripts were detected in seeds as well as in vegetative tissues while BnTT16 expression was restricted to the seed, as shown for the Arabidopsis corresponding genes (Walker et al. 1999; Nesi et al. 2000, 2002; Baudry et al. 2006). Accumulation of the targeted transcripts was detected as early as 5 dap (even in floral buds for BnTT16 and BnTTG1), consistent with the fact that ProAtBAN was activated as soon as early seed developmental stages (1-2 dap). In addition, expression profiles of BnTT8 and 
BnTT16 were restricted to the seed integuments that corroborated the patterns of PA accumulation and of ProAtBAN activation in B. napus seed.

Future prospects of this work will report the identification of rapeseed homologs for most of the known TT-like genes, including $B A N$, establishing that flavonoid metabolism is active in B. napus seeds and highly conserved between Arabidopsis and Brassica genus.

Acknowledgments Prof. Bernd Weisshaar and Dr. Martin Sagasser are acknowledged for sharing unpublished results and for critically reviewing the manuscript. We thank Genoplante for the kind gift of the Brassica napus cDNA clones BN15023K07, BN20042P19 and BN25061A20. The authors are grateful to all the members of the Brassica group from INRA Le Rheu for supporting this job, especially towards Marie-Thérèse Fournier for careful preparation of plant samples. Laurent Charlon, Loïc Daniel and Patrick Rolland are acknowledged for supplying greenhouse services. Part of this work was funded through a GABI-Genoplante collaborative project (CompGen: "Comparative genomics between Arabidopsis and Brassica for genes directing seed-specific flavonoid biosynthesis"). B.A. is the recipient of a Région de Bretagne 3-years PhD fellowship (grant nb. 06007978).

Open Access This article is distributed under the terms of the Creative Commons Attribution Noncommercial License which permits any noncommercial use, distribution, and reproduction in any medium, provided the original author(s) and source are credited.

\section{References}

Altschul SF, Gish W, Miller W, Myers EW, Lipman DJ (1990) Basic local alignment search tool. J Mol Biol 215:403-410

Batchelor AK, Boutilier K, Miller SS, Labbe H, Bowman L, Hu M, Johnson DA, Gijzen M, Miki BLA (2000) The seed coat-specific expression of a subtilisin-like gene, SCS1, from soybean. Planta 211:482-492

Batchelor AK, Boutilier K, Miller SS, Hattori J, Bowman L, Hu M, Lantin S, Johnson DA, Miki BLA (2002) SCB1, a BURPdomain protein gene from developing soybean seed coats. Planta 215:523-532

Baudry A, Heim MA, Dubreucq B, Caboche M, Weisshaar B, Lepiniec L (2004) TT2, TT8, and TTG1 synergistically specify the expression of BANYULS and proanthocyanidin biosynthesis in Arabidopsis thaliana. Plant J 39:366-380

Baudry A, Caboche M, Lepiniec L (2006) TT8 controls its own expression in a feedback regulation involving TTG1 and homologous MYB and bHLH factors, allowing a strong and cell-specific accumulation of flavonoids in Arabidopsis thaliana. Plant J 46:768-779

Becker A, Kaufmann K, Freialdenhoven A, Vincent C, Li M-A, Saedler H, Theissen G (2002) A novel MADS-box gene subfamily with a sister-group relationship to class B floral homeotic genes. Mol Genet Genomics 266:942-950

Beeckman T, De Rycke R, Viane R, Inze D (2000) Histological study of seed coat development in Arabidopsis thaliana. J Plant Res 113:139-148

Cardoza V, Stewart CN (2003) Increased Agrobacterium-mediated transformation and rooting efficiencies in canola (Brassica napus L.) from hypocotyl segment explants. Plant Cell Rep 21:599-604
Chai YR, Lei B, Huang HL, Li JN, Yin JM, Tang ZL, Wang R, Chen L (2008) TRANSPARENT TESTA12 genes from Brassica napus and parental species: cloning, evolution, and differential involvement in yellow seed trait. Mol Genet Genomics PMID: 19018571 [Epub ahead of print]

Debeaujon I, Peeters AJM, Léon-Kloosterziel KM, Koornneef M (2001) The TRANSPARENT TESTA12 gene of Arabidopsis encodes a multidrug secondary transporter-like protein required for flavonoid sequestration in vacuoles of the seed coat endothelium. Plant Cell 13:853-871

Debeaujon I, Nesi N, Perez P, Devic M, Grandjean O, Caboche M, Lepiniec L (2003) Proanthocyanidin-accumulating cells in Arabidopsis testa: regulation of differentiation and role in seed development. Plant Cell 15:2514-2531

Devic M, Guilleminot J, Debeaujon I, Bechtold N, Bensaude E, Koornneef M, Pelletier G, Delseny M (1999) The BANYULS gene encodes a DFR-like protein and is a marker of early seed coat development. Plant J 19:387-398

Dong J, Keller WA, Yan W, Georges F (2004) Gene expression at early stages of Brassica napus seed development as revealed by transcript profiling of seed-abundant cDNAs. Planta 218:483491

Durkee AB (1971) The nature of tannins in rapeseed (Brassica campestris). Phytochemistry 10:1583-1585

Haughn G, Chaudhury A (2005) Genetic analysis of seed coat development in Arabidopsis. Trends Plant Sci 10:472-477

Hills MJ (2004) Control of storage-product synthesis in seeds. Curr Opin Plant Biol 7:302-308

Huang X, Madan A (1999) CAP3: A DNA sequence assembly program. Genome Res 9:868-877

Iwanowska A, Tykarska T, Kuras M, Zobel AM (1994) Localization of phenolic compounds in the covering tissues of the embryo of Brassica napus (L.) during different stages of embryogenesis and seed maturation. Ann Bot 74:313-320

Jefferson RA, Kavanagh TA, Bevan MW (1987) GUS fusions: $\beta$ glucuronidase as a sensitive and versatile gene fusion marker in higher plants. EMBO J 6:3901-3907

Klimyuk VI, Carroll BJ, Thomas CM, Jones JD (1993) Alkali treatment for rapid preparation of plant material for reliable PCR analysis. Plant J 3:493-494

Koncz C, Kreuzaler F, Kalman Z, Schell J (1984) A simple method to transfer, integrate and study expression of foreign genes, such as chicken ovalbumin and $\alpha$-actin in plant tumors. EMBO J 3:1029-1037

Koornneef M (1981) The complex syndrom of ttg mutant in Arabidopsis. Arabidopsis Inf Serv 18:45-51

Kumar R, Singh M (1984) Tannins: their adverse role in ruminant nutrition. J Agric Food Chem 32:447-453

Lepiniec L, Debeaujon I, Routaboul J-M, Baudry A, Pourcel L, Nesi N, Caboche M (2006) Genetics and biochemistry of seed flavonoids. Ann Rev Plant Biol 57:405-430

Leung J, Fenton TW, Mueller MM, Clandinin DR (1979) Condensed tannins of rapeseed meals. J Food Sci 44:1313-1316

Li YG, Tanner G, Larkin P (1996) The DMACA-HCl protocol and the threshold proanthocyanidin content for bloat safety in forage legumes. J Sci Food Agric 70:89-101

Li Y, Beisson F, Pollard M, Ohlrogge J (2006) Oil content in Arabidopsis seeds: the influence of seed anatomy, light and plant-to-plant variation. Phytochemistry 67:904-915

Marles MAS (2001) Biochemical and molecular studies of the seed coat of Brassica carinata (A. Braun.) and other Brassicaceae. Dissertation, University of Saskatchewan, Saskatoon, Canada

Marles MAS, Gruber MY (2004) Histochemical characterisation of unextractable seed coat pigments and quantification of extractable lignin in the Brassicaceae. J Sci Food Agric $84: 251-262$ 
Marles MAS, Gruber MY, Scoles GJ, Muir AD (2003a) Pigmentation in the developing seed coat and seedling leaves of Brassica carinata is controlled at the dihydroflavonol reductase locus. Phytochemistry 62:663-672

Marles MAS, Ray H, Gruber MY (2003b) New perspectives on proanthocyanidin biochemistry and molecular regulation. Phytochemistry 64:67-383

Martin-Tanguy T, Guillaume T, Kossa A (1977) Condensed tannins of horse bean seeds: chemical structure and apparent effects on poultry. J Sci Food Agric 28:757-765

Moïse JA, Han S, Gudynaite-Savitch L, Johnson DA, Miki BLA (2005) Seed coats: structure, development, composition, and biotechnology. In Vitro Cell Dev Biol Plant 41:620-644

Naczk M, Nichols T, Pink D, Sosulski F (1994) Condensed tannins of canola hulls. J Agric Food Chem 42:2196-2200

Naczk M, Amarowicz R, Pink D, Shahidi F (2000) Insoluble condensed tannins of canola/rapeseed. J Agric Food Chem 48:1758-1762

Nadeau JA, Zhang XS, Li J, O'Neill SD (1996) Ovule development: identification of stage-specific and tissue-specific cDNAs. Plant Cell 8:213-239

Nakaune S, Yamada K, Kondo M, Kato T, Tabat S, Nishimura M, Hara-Nishimura I (2005) A vacuolar processing enzyme, $\delta$ VPE, is involved in seed coat formation at the early stage of seed development. Plant Cell 17:876-887

Nesi N, Debeaujon I, Jond C, Pelletier G, Caboche M, Lepiniec L (2000) The TT8 gene encodes a basic helix-loop-helix domain protein required for expression of $D F R$ and $B A N$ genes in Arabidopsis siliques. Plant Cell 12:1863-1878

Nesi N, Jond C, Debeaujon I, Caboche M, Lepiniec L (2001) The Arabidopsis TT2 gene encodes an R2R3 MYB domain protein that acts as a key determinant for proanthocyanidin accumulation in developing seed. Plant Cell 13:2099-2114

Nesi N, Debeaujon I, Jond C, Stewart AJ, Jenkins GI, Caboche M, Lepiniec L (2002) The TRANSPARENT TESTA16 locus encodes the ARABIDOPSIS BSISTER MADS domain protein and is required for proper development and pigmentation of the seed coat. Plant Cell 14:2463-2479

O'Brien TP, Feder N, McCully ME (1964) Polychromatic staining of plant cell walls by Toluidine Blue O. Protoplasma 59:367373

Pang Y, Peel GJ, Sharma SB, Tang Y, Dixon RA (2008) A transcript profiling approach reveals an epicatechin-specific glucosyltransferase expressed in the seed coat of Medicago truncatula. Proc Natl Acad Sci USA 105:14210-14215

Porter LJ, Hrstich LN, Chan BG (1986) The conversion of procyanidins and prodelphinidins to cyanidins and delphinidins. Phytochemistry 25:223-230

Pourcel L, Routaboul JM, Kerhoas L, Caboche M, Lepiniec L, Debeaujon I (2005) TRANSPARENT TESTA10 encodes a laccase-like enzyme involved in oxidative polymerization of flavonoids in Arabidopsis seed coat. Plant Cell 17:2966-2980

Rahman MH (2001) Production of yellow-seeded Brassica napus through interspecific crosses. Plant Breeding 120:463-472

Ren C, Bewley JD (1998) Seed development, testa structure and precocious germination of Chinese cabbage (Brassica rapa subsp. pekinensis). Seed Sci Res 8:385-397
Routaboul J-M, Kerhoas L, Debeaujon I, Pourcel L, Caboche M, Einhorn J, Lepiniec L (2006) Flavonoid diversity and biosynthesis in seed of Arabidopsis thaliana. Planta 224:96-107

Sagasser M, Lu GH, Hahlbrock K, Weisshaar B (2002) A. thaliana TRANSPARENT TESTA 1 is involved in seed coat development and defines the WIP subfamily of plant zinc finger proteins. Genes Dev 16:138-149

Schuurmans JAMJ, van Dongen JT, Rutjens BPW, Boonman A, Pieterse CMJ, Borstlap AC (2003) Members of the aquaporin family in the developing pea seed coat include representatives of the PIP, TIP, and NIP subfamilies. Plant Mol Biol 53:655-667

Schwetka A (1982) Inheritance of seed colour in turnip rape (Brassica campestris L.). Theor Appl Genet 62:161-169

Simbaya J, Slominski BA, Rakow G, Campbell LD, Downey RK, Bello JM (1995) Quality characteristics of yellow-seeded Brassica seed meals: protein, carbohydrates, and dietary fiber components. J Agric Food Chem 43:2062-2066

Slominski BA, Simbaya J, Campbell LD, Rakow G, Guenter W (1999) Nutritive value for broilers of meals derived from newly developed varieties of yellow-seeded canola. Anim Feed Sci Tech 78:249-262

Todd JJ, Vodkin LO (1993) Pigmented soybean (Glycine max) seed coats accumulate proanthocyanidins during development. Plant Physiol 102:663-670

Vancanneyt G, Schmidt R, O'Connor-Sanchez A, Willmitzer L, Rocha-Sosa M (1990) Construct of an intron-containing marker gene: splicing of the intron in transgenic plants and its use in monitoring early events in Agrobacterium-mediated plant transformation. Mol Gen Genet 220:245-250

Walker AR, Davison PA, Bolognesi-Winfield AC, James CM, Srinivasan N, Blundell TL, Esch JJ, Marks MD, Gray JC (1999) The TRANSPARENT TESTA GLABRAl locus, which regulates trichome differentiation and anthocyanin biosynthesis in Arabidopsis, encodes a WD40 repeat protein. Plant Cell 11:1337-1350

Wan L, Xia Q, Qui X, Selvaraj G (2002) Early stages of seed development in Brassica napus: a seed coat-specific cysteine proteinase associated with programmed cell death of the inner integument. Plant J 30:1-10

Wei YL, Li JN, Lu J, Tang ZL, Pu DC, Chai YR (2007) Molecular cloning of Brassica napus TRANSPARENT TESTA 2 gene family encoding potential MYB regulatory proteins of proanthocyanidin biosynthesis. Mol Biol Rep 34:105-120

Wu SP, Druka A, Horvath H, Kleinhofs A, Kannangara CG, von Wettstein D (2000) Functional characterization of seed coatspecific members of the barley germin gene family. Plant Physiol Biochem 38:685-698

Xie D-Y, Sharma SB, Paiva NL, Ferreira D, Dixon RA (2003) Role of anthocyanidin reductase, encoded by BANYULS in plant flavonoid biosynthesis. Science 299:396-399

Xu BB, Li J-N, Zhang X-K, Wang R, Xie L-L, Chai Y-R (2006) Cloning and molecular characterization of a functional flavonoid 3'-hydroxylase gene from Brassica napus. J Plant Physiol 164:350-363

Zeng CL, Wang J-B, Liu A-H, Wu X-M (2004) Seed coat microsculpturing changes during seed development in diploid and amphidiploid Brassica species. Ann Bot 93:555-566 